\section{Adaptability of Pecan as a Species}

\author{
Darrell Sparks \\ Department of Horticulture, University of Georgia, Athens, GA 30602
}

Additional index words. Carya illinoinensis, ecology, native habitat, distribution

\begin{abstract}
Pecan [Carya illinoinensis (Wangenh.) C. Koch] is indigenous to the Mississippi River drainage system of the United States. Climate in the native pecan region ranges from humid to semiarid and from mild to harsh winters. Rainfall is bimodal with peaks in March to April and in August to September. Pecan is site specific and is the climax tree species on loamy, well drained, first bottom river land with a relatively high water table. Detrimental effects from pecan's shade intolerance from its more vigorous, sympatric species are minimized as these species are specific to differ sites. Pecan's deep and phreatophytic rooting habit ensures soil moisture during drought periods and facilitates pecan's survival in semiarid regions. Root development in the humus-surface layer ensures nutrient uptake from the most nutrient rich layer of the soil and, when the lower soil profile is saturated, aeration for the roots and water and nutrient uptake. The bimodal rain pattern replenishes soil profile moisture and its timing ensures seed germination, stand establishment, well-developed seed, and minimal drought stress. Natural selection for freeze tolerance and for minimum fruit development time allows survival in areas with harsh winters and short growing seasons. Regulation of seed germination and budbreak by heating and chilling results in pecan being native in cold and warm climates, greatly increasing the native range. The northern limit for pecan is dictated by heat units; the southern limit is restricted by lack of bimodal rains and vivipary. Reproductive stress is caused by the high lipid content of seed, but is counteracted by a long juvenile growth period of the seedling, by a small nut size and low percentage kernel, and by "off" production years of the tree. Nut and percentage kernel decrease as the growing season decreases which contributes to species survival in geographical regions with a short growing season. Selection for small nuts with low percentage kernel is enhanced by predators. Tree reserves are depleted by heavy production during "on" years and are replenished during "off"years. Perpetuation of pecan forests is apparently from sib/half sib seedlings following predator satiation while dissemination into new areas may be mainly by predators. Pecan and its pests successfully co-exist. Major defense against fruit feeders is escape in time, leaf feeders by biological associations and accommodation, and leaf diseases by confrontation. Heterozygous progenies from cross-pollination provide ample genetic diversity for continuous pecan selection to endure pressures imposed throughout a wide climatic range. Ecological adaptions within native pecan forests should be used in developing and maintaining commercial pecan orchards.
\end{abstract}

Pecan is a monoecious, heterodichogamous, wind-pollinated, deciduous nut tree that is indigenous to the United States. The native range follows the river bottoms of the Mississippi River and its many tributaries and the rivers of central and eastern Texas and their tributaries. In the eastern U.S., pecan extends to Clinton, Iowa, in the north, Cincinnati, Ohio, in the east, and New Orleans, La., in the south. In the western U.S., pecan extends to the Devil's River area of Texas in the west and north and to Crystal City, Texas, in the south. The southern native pecan area in Texas extends into northeastern Mexico (Flack, 1970; Hester, 1981; Sargent, 1933; USDA Bureau of Plant Industry, 1931). In the early 1930s, the trees were most abundant and reached their greatest size in southern Arkansas and eastern Texas (Sargent, 1933).

Within the native pecan area, the climate ranges from mild to extremely harsh winters and from very humid to semiarid. Pecan has adapted to a wide climatic range between 30 to $42^{\circ} \mathrm{N}$ latitude (Sparks, 1991a), suggesting substantial genetic diversity. Major differences exist among genotypes by climatic regions. Diversity occurs for growth rate, dormancy inception (Grauke, 1999; Harris and Tauer, 1987), days required for fruit growth, nut size,

Received for publication 7 Dec. 2004. Accepted for publication 31 Jan. 2005. percentage kernel, and resistance to cold injury (Sparks, 1991a, 1992a).

Pecan differs from most deciduous fruit trees in that virgin stands still exist on undisturbed sites in its native habitat, thus affording the opportunity for observation and experimental study under natural conditions. Pecans are also commercially grown in native groves (pecan forests cleared of competing trees and brush) and in orchards, mainly planted outside the native pecan range. These contrasting systems furnish insightful comparisons, especially between pecan forests and orchards.

The objective of this paper is to discuss the adaptability of pecan as a species and to propose and discuss apparent adaptive mechanisms essential to survival in native habitats. The mechanisms proposed have resulted from research and 40 years of examination of pecan field performance. Some projected mechanisms are supported by data while others are based more on observations. The more hypothetical mechanisms were proposed to stimulate research that test their validity.

\section{Site Requirements and Tree Species} Distribution within River Bottom Land

Within its native range, pecan grows on the lowest-lying portions of river bottom land, termed first bottoms. Pecans are uncommon on second bottoms (Putnam and Bull, 1932; Skinner et al., 1938). Second bottoms or terraces are old flood plains that are situated at higher elevations than first bottoms. Unless protected by dams, first bottoms, in contrast to second bottoms, are subject to flooding and have a relatively high water table. Flooding frequency varies with location and ranges from one or more times annually to as infrequently as once every 15 years or more (Greenwade et al., 1996; Huckabee et al., 1977).

Pecan is sensitive to poor drainage (Alben, 1958; Loustalot, 1945; Smith and Ager, 1988; Smith and Bourne, 1989). Prolonged flooding during dormancy is not detrimental, but suppresses shoot and root growth when it occurs during active tree growth, especially at budbreak (Smith and Bourne, 1989). Thus, distribution of pecans within first bottoms varies with soil drainage. Drainage is governed primarily by the topography and soil texture of the bottom land. Typically, first bottom topography is characterized by poorly drained, newly formed land adjacent to the river followed by higher and drier front land. High, predominantly loamy ridges (natural levees) occur next. Low, predominantly clayey flats and sloughs (nearly filled channels of former watercourses) occur further back. Uplands occur beyond the flats. Second bottoms may occur between flats and uplands. The flats can be intersected by low and, usually, loamy ridges or hummocks (formed as banks of less permanent water courses). Ridges are better drained due to higher elevation and loamy soil texture. First bottom flats are often wet due to poor surface drainage, which is accentuated by tight clays.

Pecans occur principally on well drained loamy ridges that are not subject to prolonged flooding (Putnam et al., 1960; USDA Bureau of Plant Industry, 1931). Stand size varies from less than one hectare to several 100 hectares. Within flats, pecan distribution is restrictive. Pecan is most common on the low, intersecting, loamy ridges (Putnam et al., 1960) and, on the flat proper, pecan abundance and productivity diminishes progressively as soil drainage decreases (Baker, 1979; Skinner et al., 1938). On low, poorly to very poorly drained flats, pecan is rare and these sites are occupied by sympatric tree species (Michaux, 1904; Putnam and Bull, 1932; Putnam et al., 1960; Rosborough et al., 1946; Skinner etal., 1938; Sparks, 2002a). Thus, within flats the net result is a mixed forest of pecan and sympatric species with pecan mainly on the intersecting ridges. Pecan's sensitivity to excessive soil moisture is strikingly evidenced by the decline of native pecan stands following water table elevation from dams constructed by the U.S.Army Corps of Engineers (M.W. Smith, personal communication). Tree decline also becomes a problem on loamy sites following river flooding that changes the topography via scouring and deposition so that surface drainage is impeded (Baker, 1979).

The assumption that pecan trees have a high water requirement as a result of being native to river bottoms (Boisen and Newlin, 1910; Rosborough et al., 1946) has been confirmed experimentally (Miyamoto, 1983; Worthington 
etal., 1987). Therefore, pecans do not grow well on soils with a low available water capacity, such as shallow soils or excessively drained sandy and gravelly soils (Baker, 1979), or loamy bottoms in semiarid regions where the water table is beyond pecan's rooting depth (Blum, 1982). These relationships indicate that pecan in its native habitat is site sensitive due to exacting water and soil drainage requirements. These requirements govern and restrict the distribution of pecan within river bottom land (Sparks, 2002a). Accordingly, pecan tree size and homogeneity increase sharply with site suitability (Sparks, 2002a; Wolstenhome, 1979). On preferred sites, pecan is the climax vegetation (Sparks, 2002a). Tree size can be extremely large with heights up to 45 to $55 \mathrm{~m}$ and trunk diameters up to 1.2 to 2 $\mathrm{m}$ (Boisen and Newlin, 1910; Sargent, 1933). In 80-year-old orchards, common in Georgia, there may be 12 or fewer trees per hectare. Trees 100 years old are common and maximum longevity is 380 or more years (Boisen and Newlin, 1910; Chung et al., 1995; Pecan Quart., 1976; Romberg, 1968; Sargent, 1933; Stokes et al., 1995). Lightning strikes is a major cause of death for very tall trees.

The number and kinds of sympatric species on first bottoms increase from semiarid to humid climates. Grasses are the major vegetation type forming a prairie habitat with only $10 \%$ to $25 \%$ of the ground covered by a canopy of pecan and sympatric trees in arid regions. The major sympatric tree species in these areas are black willow (Salix nigra Marsh.) and eastern cottonwood (Populus deltoides Bartr.). As the humidity increases, trees become more common and additional sympatric species are hackberry (Celtis occidentalis L.), american elm (Ulmus americana L.), and sycamore (Platanus occidentalis L.). With further increases in humidity, supplementary sympatric species are green ash (Fraxinus pennsylvanica Marsh.), sugarberry (Cletis lavigata Willd.), and willow oak (Quercus pellos L.) (Sparks, 2002a). Willow, cottonwood, and sycamore are situated on sites with shallow water tables (Putnam and Bull, 1932). Willows and cottonwoods are on newly formed land. Willows are near the river edge and cottonwoods are further back on higher and drier portions of the new land. Sycamores occur beyond the cottonwoods on the still higher and drier front land, but below the high loamy ridges most suited for pecan. The other sympatric tree species are situated on clayey flats. The preferred bottom land site indicates that the sympatric tree species, like pecan (Miyamoto, 1983: Worthington et al., 1987), have a high water requirement as shown for sycamore, willow, and cottonwood (Lee, 1942).

Pecan is the dominant Carya species in its riverine habitat (Bettis et al., 1990; Maggio et al., 1991). Water hickory [Carya aquatica (Michx. f.) Nutt.] occurs on poorly drained flats, sloughs, and margins of swamps on first bottoms (Maggio et al., 1991; Putnam et al., 1960) and, thus, does not compete with pecan. Other Carya spp. occur on second bottoms or on uplands (Putman et al., 1960). They, like pecan, are very exacting in their site requirements, especially for water. Carya spp. ranked in ascending order of moisture requirement are: pignut [(C. glabra
(Mill.) Sweet], mockernut(C. tomentosa Nutt.), shagbark [C. ovata (Mill.) Koch], bitternut [C. cordiformis (Wangenh.) K. Koch], shellbark [C. laciniosa (F. Michx.) Loudon], nutmeg [C. myristiciformis (F. Michx.) Nutt.], pecan [C. illinoinensis (Wangenh.) K. Koch], and water hickory [C.aquatica (F. Michx.) Nutt.] (Boisen and Newlin, 1910).

\section{Tree Growth and Pecan Adaptation to River Bottom Land}

Adaptation of pecan to well drained loamy bottom land sites begins with the seed. The pecan kernel contains about 70\% lipids (Watt and Merrill, 1963). Pecan seeds, relative to most seeds, are large. 'Curtis', a nut commonly used in southeastern U.S. nurseries, weighs about $5.5 \mathrm{~g}$ and contains $59 \%$ kernel; thus, the seed contains a large amount of high energy reserves.

Germination. Following seed germination, seedling growth is dependent on cotyledonal lipids for the first 3 weeks that the cotyledons remain viable and attached to the seedling (Wetzstein et al., 1983). During this dependency period, only about half of the seed's lipid content is used by the developing seedling. The long dependency and limited recycling of stored reserves contrasts markedly with the rapid depletion (4 to $14 \mathrm{~d}$ from germination) of reserve materials and the short dependency in many plants (Ching, 1963, 1966; Miller, 1938; Von Ohlen, 1931; Varner, 1965; White, 1958). During the dependency period, radicle (taproot) elongation is 20 to $25 \mathrm{~cm}$ before the epicotyl emerges, whereby conferring a competitive advantage in the acquisition of soil moisture during the critical germination period. Continued attachment of functional cotyledons after the seedling is self-sufficient permits regeneration of the top if it is destroyed early in its development. Regeneration, which is common in nature, occurs from axillary meristems on the subterranean portion of the stem and root. Hypogeal germination helps to protect the cotyledons from desiccation during the protracted germination period (Sork, 1983). The kernel remains viable during this period in spite of being susceptible to an array of decomposing microorganisms (Payne and Wells, 1984; Wells and Payne, 1976). The high tannin content of the shell's packing tissue (Avants and Pressey, 1972) or possibly other shell substances may function as natural antibiotics against kernel rots. This possibility is supported by the biological activity that has been demonstrated for the shell (Wang, 1987) and tannic acid (Woodroof, 1930). Antibiotic properties have been attributed to tannins in general (Feeny, 1976; Swain, 1965). Leaf or grass litter is the medium for natural seed stratification and, subsequently, the seed bed for pecan (Batcheller, 1980; Conner and Williamson, 1984) and other Carya spp. (Barnett, 1977; Cahalane, 1942). The duff or litter layer affords protection for the emerging epicotyl. Otherwise, exposure to bare ground and direct sunlight may result in epicotyl dieback due to the high temperatures of the soil surface (Demaree, 1927).

The large seed and hypogeal germination of pecan are also characteristic of some other forest tree species (Grime and Jeffery, 1965; Stone, 1973). The large seed and high lipid content was proposed to facilitate seedling establishment in micro habitats with reduced light intensity (Manchester, 1987; Stone, 1973). This hypothesis does not exactly fit for pecan because pecan (Baker, 1950; Boisen and Newlin, 1910; Putnam and Bull, 1932) and other Carya species (Holch, 1931; Keever, 1973; Peet and Christensen, 1980; Ranney et al., 1981; Sork, 1983) are shade intolerant. The major significance of the high lipid content and large seeds of Carya species is in providing nutritional resources to the embryo for establishing deep root systems and regenerating damaged epicotyls. However, the large lipid content does allow the seedling to become established and survive for at least a year under dense shade and, under lesser shade, the seedling may survive in an arrested stage for longer periods.

Root growth. Following the dependency period, root growth continues with the taproot growing up to $2 \mathrm{~m}$ by season's end (Toumey, 1929; Woodroof, 1933). In contrast, top growth is unbranched, determinate, and typically is limited at 12 to $30 \mathrm{~cm}$ (Boisen and Newlin, 1910; Sparks, 1986a, 1986b; Toumey, 1929; Wetzstein et al., 1983; Woodroof, 1933). Leaf number is predetermined which in 'Curtis' seedlings is at a maximum of 11 to 13 per seedling (Sparks, 1986a, 1986b; Wetzstein et al., 1983). Stem dry weight comprises only about $12 \%$ of the total weight (stem plus roots) of the seedling (White, 1982). Predominant and continuous taproot elongation during the seedling's first year helps to ensure an adequate water supply as downward root penetration keeps ahead of the descending desiccation of the soil profile during drought periods. Consequently, the chance of successful seedling establishment is increased. Only after the root system becomes established does substantial top growth begin, usually sometime after the fourth growing season (Boisen and Newlin, 1910). Extent of top growth during the first few years varies depending on the degree of herbivory, mainly by deer (Odocoileus virginianus). Preferential root development and lag top growth during early seedling development is also characteristic of other Carya species (Holch, 1931; Toumey, 1929).

During the first year, the root system consists predominantly of a taproot with weak lateral roots (Toumey, 1929). Initial root architecture is inflexible indicating tight developmental control. For example, the taproot grows around any obstruction without proliferation of lateral roots. Inflexibility was strikingly displayed in a Georgia nursery row where an abandoned road bed was buried about $30 \mathrm{~cm}$ below the soil surface. The taproot began to grow at a right angle on encountering the compacted soil of the road bed and continued to grow at a right angle parallel to the road bed surface. Proliferation of laterals did not occur, as characteristic of some other tree species (Toumey, 1929). Inflexibility further increases the probability of a deep root system and initial seedling survival via increased water availability.

Following the first few years after germination, the taproot continues to grow vertically into the soil. Final rooting depth depends on 
soil depth and drainage (Alben, 1955; Gammon et al., 1955; Kerzdorn, 1952; U. S. Dept. Agr. Bureau of Plant Industry, 1931; White and Edwards, 1978; Woodroof and Woodroof, 1934) but roots of mature trees may extend to a depth of $7 \mathrm{~m}$ or down to the water table (Kerzdorn, 1952). Pecan in its native habitat has been classified as a phreatophyte (Sparks, 2002a), a plant that characteristically roots down to the water table.

Lateral roots begin abundant development during the second year. Lateral roots develop throughout the length of the taproot but the uppermost laterals and their proximity to the soil surface (i.e., brace roots) are essential to anchoring the tree as discussed later. Initially, lateral root growth is at a slight acute angle $\left(<10^{\circ}\right)$ with respect to the taproot (Woodroof and Woodroof, 1934). However, in shallow soils, lateral roots extend perpendicular to the taproot, growing parallel to the soil surface after only a short distance (Woodroof, 1933). Limited observations indicate that downward growth extends to a greater depth in deep soils, but the positive geotropic response is eventually diminished and the roots reorientate and grows parallel to the soil surface. Lateral roots extend horizontally about two times the canopy diameter of young trees (25 years) growing on shallow soils. Observations indicate extension is much greater in old trees. The large soil volume occupied by roots increases the probability of adequate soil moisture before the water requirement of the tree canopy becomes substantial.

Vertical roots develop from the primary lateral roots (Pelham, 1928; Woodroof, 1933) at least by the fourth year (personal observations). These laterals grow vertically to the soil surface (Pelham, 1928) and fan out near the surface, especially in the interface of the soil surface and humus layer. These roots are termed humus strivers (Lyr and Hoffman, 1967). The roots are small (diameter $<1 \mathrm{~mm}$ ). Under excellent soil moisture and a heavy humus layer, these root form thin mats. This development of a high density of small absorbing roots in the humus-topsoil layer is also characteristic of other deciduous forest trees (Coile, 1937) although their origin may not be similar. Near the stage of striver root development, accelerated growth of the aerial portion of the tree begins. Co-development of rooting in the humus-topsoil layer and accelerated top growth is significant for the conversion of the tree from the juvenile stage to the reproductive stage. Roots develop in the fertile humus-topsoil by the time nutrient demand is increased from an expanding canopy and eventually from fruiting. Humus striver roots are absent in deciduous fruit trees (Atkinson, 1980).

The function of roots in uptake of water and nutrients is proposed to be dependent on the location of the roots within the soil profile. That is, roots in the humus-topsoil layer function predominantly in supplying the tree nutrients, whereas deep roots are more important in water uptake. If true, differential root function is well suited to the rainfall and flood pattern. In native pecan areas, rainfall is bimodal with the first peak occurring in March to May and the second peak occurring in August to September
(Sparks, 2002a). Consequently, flooding occurs mainly in early spring and in late fall (Smith and Bourne, 1989). The net result is that soil moisture in the profile is replenished before the onset of the growing season by either flooding or rains with accompanying runoff from uplands, or both. Once wetting ceases, nutrient uptake from the humus-topsoil is limited to the time the area retains adequate moisture. Much direct and indirect data suggest nutrient uptake in pecan is at a maximum during the early portion of the growing season (Acuna-Maldconado et al., 2003; Alben, 1946; Gammon et al., 1960; Smith and Bourne, 1989; Sparks, 1968, 1977, 1989b, 2003a; Wazir et al., 1988). Proliferation of humus striver roots in the humus-topsoil layer is an apparent adaptive survival mechanism that maximizes nutrient uptake from the most fertile area of the soil profile at the time of the year when the soil moisture is most likely to be optimum. Also, in early spring when most of the soil profile may be saturated from seasonal rains or flooding, the roots in the humus-topsoil layer are important for water uptake and aeration, as suggested by tree decline following siltation or in years following an excessively wet growing season. As the soil upper profile dries and the lower profile drains to field capacity following flooding or rains, tree survival is increasingly dependent on roots at greater depths for water. A differential function for humus-topsoil roots and deep roots is supported by the sequence of new root growth in the spring and summer. Root growth begins during shoot elongation (Lockwood and Sparks, 1978a; White and Edwards, 1978). Then, root growth occurs first in the upper most part of the topsoil (White and Edwards, 1978). As the season progresses and the soil temperature increases and drainage improves vertically through the soil profile, root growth commences at greater depths while root extension in the upper profile decreases or ceases due to descending desiccation of the soil. Beginning with rapid kernel development, root growth rapidly declines through the remainder of the growing season, regardless of soil profile position.

Indirect and direct evidence supports the hypothesis that the humus-topsoil-root association is key to the overall nutrition of pecan in nature via recycling of nutrients, mainly from decaying leaves and shucks. Substantial nutrient recycling in pecan is expected based on several factors including a) prodigious leaves are produced (Acuna-Malconado et al., 2003) creating abundant leaf litter, b) organic matter formed from foliage of deciduous trees is typically nutrient rich, especially in $\mathrm{N}, \mathrm{S}, \mathrm{B}, \mathrm{Cu}, \mathrm{Zn}$, and bases (Hibbard, 1940; Tisdale et al., 1985), c) nutrient loss from nut predation is minor due to the nut's low mineral content and the relatively low nut production per tree (Sparks, 1975), and d) the nutrient rich shuck (Diver et al., 1984; Sparks, $1975,1977)$ is returned to the soil. Definitive data exists on pecan's nutritional ecology for $\mathrm{Zn}$ which supports the significance of the roothumus layer to pecan growth. In spite of pecan's extreme susceptibility to Zn deficiency (Sparks, 1987), Zn deficiency is rarely a problem in its undisturbed, native habitat (Alben et al., 1932), regardless of a high soil $\mathrm{pH}$. Zinc deficiency may be induced by either burning of the pecan forest floor or acceleration of decomposition of the humus layer by high soil temperatures from excessive tree thinning (methods employed in establishing a pecan grove) (Rosborough et al., 1946). Similarly, Zn deficiency may occur from disruption of the humus-topsoil layer by cultivation in native groves or in orchards (Sparks, 1987, 2004a). The role of humus in $\mathrm{Zn}$ nutrition was demonstrated experimentally in studies to correct rosette, a disorder of abnormal leaf and shoot development. Rosette was eliminated by creating an artificial organic layer by mulching (Firor, 1922) and by soil additions of large volumes of organic matter (McMurran, 1919; Skinner and Demaree, 1926). Later, Alben et al. (1932) demonstrated that the direct application of $\mathrm{Zn}$ corrected rosette, thus establishing the link between $\mathrm{Zn}$ deficiency, humus-topsoil layer, and the rosette disorder. A similar role of the humus-topsoil layer has not been demonstrated for other nutrients. However, significant recycling is proposed based on lack of nutrient deficiencies in nature and on the occasional development of $\mathrm{K}$ deficiency once a pecan forest is converted to a grove. Potassium deficiency may result from destruction of the organic layer along with increased nut production, which enhances K demand (Sparks, 1977), especially in the K-rich shuck (Diver et al., 1984; Sparks, 1975, 1977).

The proposal that deep roots are critical in water uptake and tree survival is supported by root and soil depth studies during droughts and by contrasts in tree growth with and without irrigation. Tree survival increased with rooting depth and the water holding capacity of the soil during the severe, prolonged 1950s drought in the native pecan range (Alben, 1955). Similarly, drought resistance as well as pecan growth and production increase directly with soil depth in the southeastern U.S. (Gammon et al., 1955, 1963). The role of deep roots in water uptake is additionally supported by observations of a southeastern U.S. pecan orchard established under solid-set sprinkler irrigation. The root system was apparently shallow due to predominant root development in the upper soil profile. When the irrigation system became inoperative during a prolonged dry period, the trees defoliated. In contrast, trees retained their leaves in an adjacent block of nonirrigated trees. Furthermore, the detrimental effect of a shallow root system is evident following orchard abandonment in the southeastern U.S. Pecan is gradually supplanted by native trees with apparent lower water requirements, especially on the more sandy soils. However, as indicated later, supplantation is not solely due to an abbreviated and shallow root system.

A deep, extensive taproot system enhances pecan tree survival by optimizing water absorption and maximizing tree anchorage. Both allow pecan trees to attain unusual heights (Boisen and Newlin, 1910; Sargent, 1933), resulting in competitive survival advantages for sunlight and for wind pollination (discussed later). The root system also provides an additional survival advantage. Trees with a deep root system tend to break during wind storms whereas trees growing in shallow soils are uprooted (Nesbitt, 
1997; Sparks, 1992a; Sparks and Payne, 1986). Abroken tree quickly regrows and consequently, survives, whereas an uprooted tree does not.

Top growth. Juvenility in pecan may last for 15 or more years (Romberg, 1944). Branching during this period is characteristically sparse. Usually, no branches form the second year and only a few branches develop during the third year. Branches become more profuse during the fourth to seventh year with top growth increasing exponentially. However, the central shoot maintains strong apical control resulting in rapid erect growth. The erect, rapid top growth associated with prolonged juvenility projects the seedling to a more competitive position in the forest canopy. Erect growth from juvenility is enhanced by phototropism.

The erect growth habit not only projects the canopy into a more favorable sunlight position, but, in the process, produces a strong tree structure essential to supporting a massive canopy. Tree structure is strong due to the natural development of a central leader or a modified central leader with scaffold limbs that are smaller in diameter than the trunk (Wolstenholme, 1979). The lower limbs eventually shade out in dense stands and the first limb may be at a height of $15 \mathrm{~m}$ or more on a mature tree (Adams, 1976), characteristic of temperate forest trees in general.

The lag growth phase of the top during early seedling establishment coupled with pecan's shade intolerance (Baker, 1950; Boisen and Newlin, 1910; Putnam and Bull, 1932) could, in theory, be a detriment to successful establishment. Seedlings of pecan's sympatric species are much more vigorous than pecan (Fowells, 1965 ) and, thus, have the potential of shading out pecan seedlings. However, for the most part, potential shading of pecan seedlings by sympatric tree species is circumvented by differential positioning of sympatric species on noncompeting clayey sites on river bottom land (Fowells, 1965; Putnam and Bull, 1932; Sparks, 2002a). Pecan's shade intolerance does effectively curtail establishment outside its preferred loamy site (Putnam et al., 1960) in humid native river bottom land where soil moisture is less likely to be limiting because of high rainfall (Sparks, 2002a). Pecan establishment on well drained clay flats is restricted by more vigorous growth and increased shading by sympatric species that are more suited to these sites than pecan. Thus, pecan is sparse on well drained clayey sites in humid climates in its native range (Baker, 1979; Huckabee et al., 1977; Werchan et al., 1974). However, within native pecan forests, pecan seedling recruitment is more likely as a moderate-shaded understory often contains small seedlings in varying degrees of arrested growth (M. W. Smith, personal communication)

Pecan (Putnam et al., 1960) and hickories in general (Keever, 1973; Peet and Christensen, 1980) require disturbances that produce prolonged light gaps in the forest to become established successfully. Otherwise, hickory species (Ranney et al., 1981; Sork, 1983), including pecan, are forest edge-oriented. In Georgia where pecan is an introduced species that has become somewhat naturalized, pecan seedlings become established along the forest edge and in open, grassy fields but rarely within a mature forest. Prolonged light gaps are mainly significant on native sites preferred by pecan because of pecan's inability to compete with the more vigorous seedlings of sympatric tree species. Here, a prolonged light gap created by the death of a large pecan tree releases the arrested growth of understory pecan seedlings. The erect growth habit and its enhancement by phototropism (Sparks, 2004b) fill in the forest gap in a relatively short time, thus ensuring pecan as the climax forest in the appropriate ecological niche.

\section{Climatic Adaptation}

Climatic regions within the native pecan range differ widely in rainfall, frequency and severity of freezing temperatures, growing season length, and heating and chilling. The selective pressures of the diverse climate have resulted in major adaptations, which contributes to pecan's survival over a wide range of climatic conditions.

Soilmoisture. Long-term annual rainfall varies from $660 \mathrm{~mm}$ in semi arid-regions to 1300 $\mathrm{mm}$ in humid regions along the native pecan areas of the Brazos River in Texas (Sparks, 2002a). Rainfall is less than pecan's seasonal water requirement of 1000 to $1300 \mathrm{~mm}$ (Miyamoto, 1983; Worthington et al., 1987) along much of the river's length. Pecan could not survive in the semiarid regions of the river based on rainfall. Instead, survival occurs because rainfall is supplemented by flooding and/or runoff from uplands and because of pecan's phreatophytic rooting habit in relationship to the water table.

The water table in native pecan bottom land varies during the year. It is highest during winter or early spring (Greenwade et al., 1996) due to the bimodal rain pattern (Sparks, 2002a) with the concomitant runoff from uplands (Rosborough et al., 1946) and accompanying floods, when they occur. The water table typically descends deeper into the soil as the growing season progresses from spring until late summer. Accelerated rains in early spring or receding flood waters ensure surface soil moisture during the nut germination period. The downward and continuous root growth precedes the descending and seasonal desiccation of the soil profile and increases the probability of pecan seedling establishment. The annual cycle of soil moisture replenishment from flooding, rain, and/or winter rise of the water table continues to give pecan trees a survival advantage in the years following initial seedling establishment. Deep alluvial soils of the native pecan range can retain large volumes of water that sustain the tree between the bimodal rains. For example, about half of pecan's seasonal water requirement of 1000 to $1300 \mathrm{~mm}$ (Miyamoto, 1983; Worthington et al., 1987) can be stored in a 4 m deep soil with an available water holding capacity of $1.6 \mathrm{~mm} \cdot \mathrm{cm}^{-1}$. The utility of the large and deep soil volume occupied by pecan roots and a relatively high water table is evident from independence of stand density on long-term, annual rain (Sparks, 2002a). Tree density is the same in semiarid and humid areas because pecan roots occupy a large, deep soil volume that can adapt to the level of the water table.

A water table within range of the roots is paramount to pecan's long term survival in its native habitat regardless of soil depth and the amount of stored moisture. Pecans in semiarid regions are restricted to long narrow bands along the river, dictated by a water table within the roots' reach. In native areas with more moderate rainfall, pecans may become established on deep loamy soils on second bottoms or other areas outside first bottoms. However, trees on these areas die during prolonged droughts as occurred in the 1950s (Alben, 1955) and from 1999-2002(W. Reid, personal communication), which provides further evidence that pecan's phreatophytic rooting habit and accessability of roots to the water table are essential for pecan survival.

Pecan in semiarid regions can be shallow rooted although characteristically the species is deep rooted. Pecans are situated on very narrow strips (about 30 to $300 \mathrm{~m}$ ) of well drained loamy soil adjacent to the Neuces River in semiarid southwest Texas, near the limit of pecan's southwestern native range. Pecan trees often abut the river's edge. At times the water table is $<1 \mathrm{~m}$ below the soil surface. The roots grow downward in response to the gradual drop in the river level and the accompanying soil water table during drought periods, again implicating the requirement for phreatophytic rooting. The trees are not subject to windthrow, apparently due the protective effect of deep river banks on either side of the river. In this area, rainfall is not bimodal as along the semiarid portions of Colorado and Brazos rivers (Sparks, 2002a). The result is that seed germination and seedling establishment occur only if the sporadic rains and/orfloods happen to coincide with the period of seed germination.

Pecan is resistant to severe droughts of moderate duration in spite of its high water requirement. Shoot growth is short and leaves are small in the spring of a second year of a severe drought (personal observations), thus, the tree's water requirement is reduced but a normal leaf moisture level is maintained (Finch and Van Horn, 1936). If drought persists, dieback is initially limited to branches in the tree top and continuously progresses downward into the crown with the duration of the drought (Sparks, 2003b). Once long droughts are over, tree vigor is quickly restored. The exception occurs when a severe drought begins in a year of heavy fruit set. Then, 3 or more years may be required for full vigor restoration, assuming the tree does not die. Drought resistance allows tree survival during periods when soil moisture is less than the seasonal optimum of 1000 to $1300 \mathrm{~mm}$ determined by Miyamoto (1983) and Worthington et al. (1987).

Although long-term total rainfall does not directly influence stand density, the timing of the seasonal bimodal rainfall pattern (Sparks, 2002a) directly affects seed germination, stand, seed production, and drought stress. The March to May rain period coincides with the grand flush of shoot and leaf expansion. However, the rainfall effect on shoot and leaf growth should 
be minimal as the water table is normally near its maximum height at this time. Instead, the greater effect may be on seed germination and initial seedling establishment and by providing soil moisture for annual nutrient uptake by roots in the humus-topsoil layer.Adequate moisture in the leaf and/or grass litter is critically important during germination as the litter is the major component of the seed bed. Nuts of Carya spp., in general, are buried by squirrels (Sciurus spp.) only 0.5 to $2.5 \mathrm{~cm}$ in the soil with the nuts often protruding above the soil surface (Cahalane, 1942; Lewis, 1982). The burial site is covered with litter. Burial of pecans and other deciduous tree nuts by crows (Corvus brachyrhynchos) and blue jays (Cyanocitta cristata) is similar (Batcheller, 1980; Vander Wall, 1990). The June to July decrease in rainfall suppresses nut volume, the significance of which is discussed later. The August to September elevation in rainfall coincides with kernel development. The 4-week period during kernel development is the most stressful period of fruit growth (Davis and Sparks, 1974) and is critically dependent on adequate soil moisture (Sparks, 1992a, 1996). The stress of kernel development and the accompanying water requirement causes the tree to be more sensitive to drought damage at this time than at any other time of the year (Sparks, 2003b). Thus, August to September rains maximize seed development and minimize fruiting stress. The timing of the August to September rains is ideal as the water table is at its seasonal low. The bimodal rain pattern in pecan's native areas increases species fitness via well-filled seeds and maintenance of tree vigor.As indicated earlier, the bimodal rain pattern does not occur along the Neuces River of Texas and is one of the factors limiting the southwestern distribution of native pecan.

Pecan root growth is ideally adapted to the seasonal rain pattern and resulting dynamics of available soil water characteristic of its native area. Small roots die once the soil dries but new growth resumes within $48 \mathrm{~h}$ of rewetting (Woodroof, 1933). Drought induced reduction in photosynthetic rate is restored within $2 \mathrm{~d}$ of rewetting (Loustalot, 1945).

Freeze tolerance. The broad-spectrum of temperature (Sparks, 1991a, 2000b) across the native pecan range has resulted in a wide diversity in cold tolerance. Genotypes from northern areas are strikingly more resistant to cold injury than are genotypes found in the south (Cochran, 1930; Smith et al., 1993a; Michigan State BoardAgr., 1898). Northern genotypes can be exceptionally hardy and have withstood -34 to $-40{ }^{\circ} \mathrm{C}$ (Campbell, 1995, Dickum, 1994).

Juvenile trunks (seedlings) from either southern or northern pecan sources are markedly more resistant to freeze injury than are nonjuvenile trunks (produced by grafting cultivars onto seedling roots) (Guengerich et al., 1967; Sparks and Payne, 1977). A juvenile trunk increases the chance of seedling survival as lethal freeze damage more commonly occurs on nonjuvenile trunks near the soil surface (Sparks and Payne, 1978) where ambient temperatures are usually lower. The protective effect afforded by juvenility is not restricted to the trunk's base and extends throughout the crown. Crown protection is apparent in that cultivars with nonjuvenile trunks can suffer extensive freeze damage throughout the crown; the same cultivar budded onto a juvenile trunk has no freeze injury. Although juvenile trunks are more resistant to freeze injury than nonjuvenile trunks regardless of geographic origin (Guengerich et al., 1967; Sparks and Payne, 1977), juvenile trunks from northern origin are much more resistant than those from southern sources (Michigan State Board Agr., 1898). The genetic diversity in cold resistance is a dominant factor in the northern distribution of native pecan.

Growing season length. The gradation in growing season length (frost-free days) from the southern to the northern native pecan areas is associated with a concomitant gradation in time required for pecan fruit development (budbreak to shuck dehiscence). Days required for fruit development increase from about 140 to 200 as the latitude decreases from $42^{\circ}$ to $30^{\circ} \mathrm{N}$ (Sparks, 1991a). Time required for fruit development increases as growing season increases from about 180 to $210 \mathrm{~d}$, suggesting that within this range, time required for fruit development is proportional to the selective pressure of the climate. When the growing season is $<180 \mathrm{~d}$, climate apparently sets the upper limit of time for fruit development, but the time stabilizes and does not vary with length of the growing season, indicating a genetically imposed upper limit of minimum time for fruit development. At a growing season longer than about $210 \mathrm{~d}$, genetics likewise apparently dictates maximum days used for fruit development.

Although genetics and climate may set the upper limit for minimum and maximum time of fruit development, unusual early maturing genotypes occur in low frequency regardless of climatic regions (Sparks, 1991a). The frequency is low because there is a selection pressure against unusually early maturing genotypes. Depredation of early maturing nuts by birds and mammals restricts the reproductive rate, thereby decreasing the frequency in nature of early maturing genotypes compared to later maturing genotypes. This concept is supported by feeding habits of eastern fox squirrels (Sciurus niger) and red-bellied woodpeckers (Centrus carolinus). Squirrels begin feeding on nuts during the liquid endosperm developmental stage before the nut develops the capacity to germinate, and woodpeckers, just before fruit ripening (Hall and Smith, 1984). During the early portion of the ripening season, the nuts are used as an immediate food source so that caching is infrequent(Leppla, 1980). Reproductive chance is further reduced because early nuts tend to be smaller than the norm (Sparks, 1991a), which are preferred by both squirrels and woodpeckers (Hall and Smith, 1984). Natural selection for early maturing genotypes greatly extended the northern distribution of pecan in spite of the selection against exceptionably early nut maturity due to animal predation.

Heating and chilling. Although pecan must have sufficient freeze tolerance to withstand northern winters and a growing season sufficiently long for fruit development, neither imposes the absolute limit for the northern distribution of pecan. Northern pecan genotypes, when established by man, can survive well north of their natural range (Bernard, 1980; Campbell, 1991; Guidi, 1979; Jaynes, 1976; Michigan State Board Agr., 1898 ). Instead, the factor limiting pecan's northern native range is the amount of heat received during the growing season (Bernard, 1980; Campbell, 1991; Dabb, 1979; Jaynes, 1976).

Northern pecan cultivars grown in Hamden, Connecticut usually fail to mature nuts even though the growing season length is equal to or greater than that required for the same cultivars when grown in the northern area of their native range (Jaynes, 1976). The difference is in seasonal heat accumulation. Heat accumulation in Hartford, Connecticut is about $20 \%$ less than Clinton, Iowa, the northern limit for native pecan. Jaynes (1976) proposed that an average seasonal total above 555 heat units (base $18.3^{\circ} \mathrm{C}$ ) is required for pecan to successfully fruit. However, because time of nut maturity is directly proportional to early spring temperatures (Sparks, 1989c), the cooler springs in Hartford delay fruit maturity, not total seasonal heat units.

Regulation of budbreak by heating and chilling(Sparks, 1993; Wolstenholme, 1970) impacts pecan's geographic distribution. Heat required for spring budbreak decreases as winter chill accumulation increases. In cold winter regions, such as, Illinois, the high chilling received in the winter enables buds to break with minimum heating in the springtime. Growth commences within minimum time, thus increasing the probability that the fruiting cycle will be completed within the short growing season associated with cold areas. On the other extreme, the lack of an obligate chilling requirement contributes to pecan's survival in regions with little or no chilling (base $3.9^{\circ} \mathrm{C}$ ), such as, in southwest Texas. Budbreak regulation by heating and chilling is an adaptive survival mechanism resulting in pecan being native over a wide geographic and climatic range within the United States. The apparent decreasing efficiency of minimum heating temperatures (i.e., $<2.2^{\circ} \mathrm{C}$ ) on budbreak (Sparks, 2003c) may also be an adaptive survival mechanism. The less-sensitive response to lower heating temperatures delays budbreak and minimizes the chance of damage from late spring freezes. This mechanism is evident in the southeastern U.S. where pecan is one of the last tree deciduous species to break bud in the spring. The same is true in the native pecan range of Texas(Maggio etal., 1991), Oklahoma, Kansas, and Missouri (M. W. Smith, personal communication).

\section{Reproductive Strategies}

Dichogamy and pollination. There are several contrasting features between staminate and pistillate flower development in pecan. Once a seedling reaches sexual maturity, staminate flowers are produced 1 to 2 years before pistillate flowers (Romberg, 1944). Production of staminate flowers first on a given seedling is not advantageous as pecan is normally crosspollinated. However, in the population as a whole, first development of staminate flowers ensures available pollen once pistillates are 
produced. Furthermore, staminate development is buffered against adversity to a greater extent than pistillate production. Morphological development of staminates begins in the spring in the year before anthesis or about 12 months before attaining maturity (Wetzstein and Sparks, 1984). In contrast, morphological development of pistillate flowers occurs in the spring of its anthesis (Wetzstein and Sparks, 1983). Staminate development mainly depends on substrates from 2 years, but pistillate development is primarily dependent on substrates from only 1 year (Lockwood and Sparks, 1978a). Consequently, staminates are produced more regularly than pistillates (Woodroof, 1930). Only rarely are pistillates produced without accompanying staminates. The net result is an available pollen source once pistillates are produced, thus ensuring reproductive chance.

Restriction of female flower development in pecan to the spring of its anthesis is unlike most deciduous fruit trees. The inflorescence in pecan is borne terminally on the shoot as in fruit species with this constriction of time between flower development and anthesis (Westwood, 1978). Stored substrates are decreasingly allocated in the spring from the shoot base to the terminus (Lockwood and Sparks, 1978a). As a result, pistillate flowers are undeveloped on weak shoots (Sparks, 1988; Yates and Sparks, 1994) and all or a portion of the pistillate cluster is aborted during the first drop (Sparks 1988; Sparks and Madden, 1985). Pistillate abortion is a survival mechanism that adjusts crop load following a stressful year, increasing the chance of vigor restoration and tree survival.

Freezing temperatures occurring 8 to $10 \mathrm{~d}$ before budbreak often results in both pistillate and staminate flower development at the shoot terminus (Sparks, 1992d). Pollen produced resulting from the abnormal flowering pattern will germinate (I.E. Yates and D. Sparks, unpublished data); however, the ecological significance, if any, of this flowering abnormality is not apparent and may be a recapitulation of the ontogeny of pecan.

Cross-pollination of pecan ensures heterozygous progeny (Marquard, 1988; Wood and Marquard, 1992) and increases survival of seedlings with sufficient genetic diversity to endure the selective pressures imposed throughout a wide climatic range. Cross-pollination is promoted by dichogamy. When selfing occurs (incomplete dichogamy), fruit abortion is increased (Romberg and Smith, 1946; Sparks and Madden, 1985; Wolstenholme, 1969) and kernel development is suppressed (Marquard, 1988; Romberg and Smith, 1946). Both increased fruit abortion and suppressed kernel development reduce the chance of reproducing genotypes with a selfing tendency. Personal observations from controlled backcrosses and limited data (Romberg and Smith, 1946) indicate that seedlings resulting from self- or sib-pollination can be low vigor. In a forest setting, low vigor pecan seedlings are more apt to die of shading by more vigorous ones. Generally, dichogamy is complete in colder climates and is often incomplete in warm climates (Sparks, 1992a). Complete dichogamy in northern climates ensures maximum diversity for key survival traits such as cold tolerance and early nut maturity.

Because pecan is wind-pollinated, genotypes producing massive volumes of pollen are more apt to transfer genetic traits than those producing scant pollen. Thus, most pecan genotypes produce prodigious pollen, characteristic of wind-pollinated species. A high volume is ensured in pecan as most buds along the length of the 1-year-old branch break (Sparks, 1992a) and each produces two to four catkin groups (Wetzstein and Sparks, 1984). The long, threeament pendulous catkins with exposed anthers are ideally adapted for wind pollination. Catkins of protogynous genotypes are longer (Stuckey, 1916; Woodroof, 1930) and have more flowers (Woodroof, 1924) than those of protandrous genotypes. The longer catkin, and presumably more pollen, compensates for pollen filtration within the tree as foliage is more advanced during a dehiscence of protogynous anthers than during a protandrous anther dehiscence (Sparks, 1992a). Tree height increases the efficiency of wind pollination as wind velocity increases with height (Whitehead, 1969) and influences the distribution plume. Tree height is especially advantageous in mixed forests where pecan trees may be widely spaced, e.g., flats with intersecting ridges. Pecan pollen is transported at least $900 \mathrm{~m}$ by wind with a density sufficient to affect limited pollination(Woodroof, 1930). The study was conducted in a small pecan planting. Pollen density would be expected to be much higher from a large pecan stand. Pollen ornamentation and wall structure are remarkably uniform in modern and fossil Carya spp. (Manchester, 1987). Manchester suggested the stability of these features represents an optimum combination for wind dispersal, hence, no sustained evolutionary change has occurred.

The exposed stigma is also well-adapted to wind pollination. The small diameter minimizes the surface boundary layer thus increasing pollen collection efficiency (Whitehead, 1969). The cone-shaped stigma increases the surface area without increasing the diameter. Collection efficiency is further enhanced by small diameter-ornate extensions of the stigma surface (Woodroof and Woodroof, 1926) and, possibly, by the rounded papillate surface cells (Wetzstein, 1989).

Pollen release is inhibited by increasing humidity and decreasing temperature (Woodroof, 1930; Yates and Sparks, 1993). High humidity inhibition is commonly observed under field conditions, as anther dehiscence does not occur during dewy mornings and rainy periods. Once the humidity drops following prolonged periods of rain, pollen release is massive and, on a breezy day, pollen from a large orchard is readily visible as a yellow fog. Inhibition of anther dehiscence by high relative humidity is an apparent survival mechanism associated with wind pollen dispersal. Pollen release during rains would limit pollen distribution both by increase in pollen weight, hence the distance the plume would disperse, and by lack of uniform distribution by winds. Pollen release with high temperature and low relative humidity ensures distribution from concomitant moderate turbulence and adequate winds. Decrease in relative humidity and pollen release by midmorning ensures adequate temperatures forpollen hydration, germination, tube elongation, and tube penetration of the stigmatic surface before the onset of unfavorable night temperature associated with springtime (Yates and Sparks, 1993).

Minimization of reproductive stress. Fruiting in pecan significantly depletes reserves present within the tree, creating a stress within the tree (Sparks, 2003c). Initially, fruit growth is slow and fruiting stress is minimal (Davis and Sparks, 1974 ) as only about $20 \%$ or less of the total dry weight accumulates during the first half of the fruit's growth cycle (Diver et al., 1984; Sparks, 1986c; Thor and Smith, 1935). During the second half of the growth cycle, fruiting stress increases rapidly and reaches a maximum during the development of the energy-rich kernel (Davis and Sparks, 1974). Pistillate flowers may be totally inhibited or suppressed to varying degrees in years following excessive fruiting (Sitton, 1931; Sparks 1983; Sparks and Brack, 1972). The tree is said to be "on" when flowers are in abundance versus "off" when flowers are weak, scant, or absent. This fruiting pattern is often described as alternate (Sparks, 1983); but it is more correctly termed irregular (Chung et al., 1995; Sparks, 1996, 1997b) because return bloom is greatly affected by environmental conditions besides fruiting stress (Sparks, 1996, 1997b).

Heavy fruiting suppresses the accumulation of carbohydrate reserves (Smith and Waugh, 1938; Wood, 1986, 1989, 1995; Worley, 1979) and depletes N, P, and K reserves (Hunter and Hammar, 1957; Krezdorn, 1955; Smith and Waugh, 1938; Sparks, 1977). Reserves are replenished during the "off" year (Hunter and Hammar, 1957; Krezdorn, 1955; Smith and Waugh, 1938; Wood, 1989, 1995; Worley, 1979). Depletion of N, P, and K, which can be associated with massive premature defoliation, occurs because any uptake during rapid fruit growth is apparently insufficient to compensate for the rapid influx of these elements into the fruit (Sparks, 1977) and, as a result, a portion of the nutrients for fruit growth comes from the leaves. The levels of N, P, and $\mathrm{K}$ in the leaf gradually decrease from year to year in the rare cases where trees fruit excessively for several consecutive years (Hunter and Hammar, 1952). In such cases there is no "off" year to replenish $\mathrm{N}, \mathrm{P}, \mathrm{K}$, and carbohydrates and the tree becomes devitalized and, in severe cases, dies (Hunter and Hammar, 1948). Thus, "off” or light years are essential for the tree's survival in nature. Tree decline is not necessarily gradual. Dieback may occur in the spring following extreme fruiting stress on a prolific tree with a large nut and high percentage kernel even if the tree otherwise appears healthy (Sparks, 2003c). The exhaustive nature of fruiting hampers survival of highly precocious and prolific genotypes. Trees stunted or dying back from excessive fruiting will be shaded out by less prolific and thus more vegetatively vigorous trees. Moreover, prolific genotypes, when fruiting excessively, are more susceptible to injury from fall and winter freezes (Smith and Cotten, 1985; Smith et al., 1993a, 1993b). Consequently, extremely precocious genotypes would be expected to be, 
and are, relatively rare in nature, especially those producing a large nut with a high percentage kernel. Fruiting stress and potential dieback is mainly a problem with cultivars selected for high production per tree, large nut size, and high percentage kernel. With more moderately productive cultivars, dieback seldom occurs, instead, shoot vigor and leaf size are suppressed the following season (Sparks, 2003c).

Return bloom in pecan has been proposed to be either directly or indirectly associated with the amount of carbohydrate reserves (Davis and Sparks, 1974: Lockwood and Sparks, 1978a; Malstrom, 1974; Smith and Waugh, 1938; Smith et al., 1986; Sparks, 1969, 1974, 1983; Worley, 1979; Wood, 1989, 1995). Following critical reappraisal of published data, floral induction (the chemical signal for the bud to form a flower) was proposed to be inhibited by the presence of the fruit, as such, whereas flower development the following spring is controlled by reserve carbohydrates (Sparks, 2000a, 2003c). Furthermore, induction was proposed to be shoot specific. More pistillate flowers are produced by a vegetative than a fruiting shoot the following spring even though carbohydrates reserves may be the same in both shoots. This response is observed both for randomly selected shoots on the tree, as well as for adjacent shoots within a branch. Floral induction (Amling and Amling, 1983), or lack of, precedes carbohydrate suppression from the stress of kernel development (Davis and Sparks, 1974). If fruiting as such is sufficient to inhibit floral induction, carbohydrates are simultaneously suppressed. Once induction occurs, carbohydrates, primarily in the roots (Lockwood and Sparks, 1978b), serve as substrates for flower development (Lockwood and Sparks, 1978a) and their amount determines the degree of return bloom, hence, the erroneous appearance of a casual relationship between floral induction and carbohydrates (Malstrom, 1974; Worley, 1979; Wood, 1989, 1995).

In addition to "off" production years, reproductive stress in pecan is minimized in nature by three other endogenous mechanisms, i.e., a long juvenile period, small nut size, and low percentage kernel. The long juvenile period (Romberg, 1944) delays fruiting and its stress. Meanwhile, the tree obtains a more competitive position in the pecan forest via rapid, upright growth. In effect, the length of the juvenile period controls the degree of precocity. It also partially controls prolificacy as precocity and prolificacy are correlated (Sparks, 1990). A long juvenile period serves as a natural selection mechanism against precocity, which in turn, minimizes fruiting stress once the tree matures.

Fruiting stress is minimized in native pecan populations because the typical pecan seed in nature is small with a thick shell (Romberg, 1968) and, thus, has a low percentage kernel. Energy for nut production is reduced because fewer nutritional reserves are metabolized to develop a small nut, especially if the percentage kernel is low. Nut size or volume increases dramatically with soil moisture (Sparks, 2002b). The promotive effect of soil moisture on nut volume is minimized in pecan's native habitat, as the period of rapid increase in nut volume coincides with the June to July period of low rainfall (Sparks, 2002a). Production per tree decreases with decreasing nut size (Sparks, 1992c). Thus, in addition to fruiting stress reduction via a small nut with a low percentage kernel, stress is further reduced by low production per tree.

As the growing season length decreases from south to north, nut size and percentage kernel likewise decrease (Sparks, 1991a). Because of the inverse relationship between production and nut size (Sparks, 1992c), production per tree decreases with increasing latitude. Near the northern limit for pecan, production is especially low (Campbell, 1976). Thus, the balance between reproductive and vegetative growth is maintained via a simultaneous reduction in nut size, percentage kernel, and nut production per tree as the growing season decreases. This adaptive survival mechanism contributes to species survival in geographical regions with a short growing season.

Pecan nut casebearer (Acrobasis nuxvorella Neunzig) is a perennial, multivoltine insect that feeds on the fruit. Potential nut production is reduced about $10 \%$ to $50 \%$ depending on the year (Coppock, 1981). This insect functions as a natural fruit thinning agent. Thinning is especially effective because thinning occurs (Coppock, 1981) before the fruit inhibits floral induction (Sparks, 2003c) and long before fruiting stress is maximized during kernel filling (Davis and Sparks, 1974). However, the insect would be expected to increase the intensity of irregular bearing because percentage thinning is greater during the "off" year (Sparks, unpublished data).

During most years in native stands, fruiting stress is minimized and adequate reserves of carbohydrates and $\mathrm{N}, \mathrm{P}$, and $\mathrm{K}$ are ensured. However, periodically, excessive production occurs and is highly synchronized over a wide geographic range (Chung et al., 1995; Gemoets etal., 1976; Wood, 1993), a phenomenon termed masting. Essentially all trees mast during the same year so that reserves during the current year and vigor the following year are equally suppressed. Thus, all trees in the pecan forest are afforded uniform competitive advantages.

Although the balance between energy for reproductive and vegetative growth normally shifts to reproductive growth (Davis and Sparks, 1974) as the fruit develops, severe environmental stress can alter the balance. Drought stress imposed before the onset of kernel development induces fruit abortion, but not leaf abscission (Gammon et al., 1955; Sparks, 1989a). The greater sensitivity of the fruit to moisture stress suggests another adaptive survival mechanism for the tree. Fruit abortion before kernel development minimizes fruiting stress and thus total stress (drought plus fruiting) on the tree. However, once rapid kernel development begins, seed production takes priority over tree survival (Sparks, 1989a). Severe drought stress imposed at this stage induces leaf abscission, but not fruit abortion. Reproductive priority following initiation of kernel growth is also triggered during an abrupt reduction in soil moisture as may occur in September on sandy soils of the southeastern U.S. Leaves die sud- denly and remain attached on fruiting but not on nonfruiting shoots, suggesting water movement to the fruit at the expense of the leaves. Similarly, movement of $\mathrm{N}, \mathrm{P}$, and $\mathrm{K}$ from the leaves to the fruit may occur to the point that the leaves scorch and defoliate on trees with excessive fruit (Sparks, 1977). Leaves scorch on fruiting but not on nonfruiting shoots, as occurs with severe drought. Reproductive priority continues through nut maturity. Fruit on cotton root rot [Phymatotrichum omnivorum (Shear) Duggar] infected trees mature 7 to $10 \mathrm{~d}$ before fruit on healthy trees. Shucks on trees with excessive fruit dehisce prematurely, which is an extreme form of reproductive priority (Sparks et al., 1995). The ultimate extreme in reproductive priority occurs when fruiting results in tree decline or death (Hunter and Hammar, 1948; Sparks, $2000 \mathrm{~b}$ ) where survival of the tree's genome is given priority over tree survival.

Vivipary (premature germination) is an unusual expression of reproductive priority. Vivipary is common in warm climates (Finch and Van Horn, 1936; Sparks, 2000b), including the southwestern limit of the native pecan range (Sparks et al., 1995). The embryo dies after germination. The reduction in viable seed along with the absence of bimodal rains, discussed earlier, hampers pecan's southwestern native distribution.

Seed dormancy. Vivipary demonstrates the seed is not dormant at the time of initial shuck dehiscence (Sparks et al., 1995). Furthermore, nuts removed and planted at incipient shuck dehiscence, germinate promptly (Tedders et al., 1970). Dormancy develops as the seed dries (Finch and Van Horn, 1936). Drying begins with shuck dehiscence. The seed remains attached to the dried shuck via vascular strands (Sparks and Yates, 1995). The strands gradually separate from the shuck and, with time, the seed is suspended by the strands, facilitating the drying process. The long suspension period ( 2 or more weeks), prevents the drop of a nondormant seed that otherwise could germinate during a warm, prolonged fall. Dormancy delays germination until conditions are conducive to seedling survival the following spring. As with budbreak (Sparks, 1993), pecan seed germination is regulated by heating and chilling (Sparks et al., 1974; Wolstenholme, 1974), allowing seed to germinate and successfully establish across a wide climatic range.

\section{Seed Dispersal Mechanisms}

Nelson(1965) suggested that water could be a major dispersal agent for pecan seed as pecan is a riverine species. Seed would be transported by flood waters and deposited as waters recede. This hypothesis assumes that pecan originated in the northern portion of the United States and the seeds were eventually dispersed downstream by flood waters to southern regions. Carya was more widely distributed across the Northern Hemisphere in the Tertiary period than it is today. Juglandaceous taxa grew as far north as Alaska and arctic Canada during the Eocene and Miocene epochs (Manchester, 1987). Thus, during the early origin of pecan, water may have been a significant dispersal agent. 
Following the Miocene epoch, there was a major climatic change during the Pleistocene epoch (Ice Age) and much of the present day temperate region was covered with ice. Studies on reforestation following glaciation retreat show that the hickories, in general, spread from an area along the Gulf of Mexico [about $18,000 \mathrm{BP}$ (before the present)] to the northern panhandle of Florida (about 14,000 BP), then northern and westward (10,000 to $6,000 \mathrm{BP})$ with the greatest concentration along the Mississippi River drainage system from the Gulf of Mexico to the southern Great Lakes (Jacobson et al., 1987). Thus, lateral and northern movement of hickories suggests factors other than water flow were dominant dispersal agents following the Ice Age. There are no sharp palynological distinctions among pollens of Carya spp. (Manchester, 1987). Thus, movement of pecan cannot be distinguished from that of other hickories but pecan had reached its present-day northern limit by at least 10,300 BP (Bettis et al., 1990).

Indians were proposed as significant contributors to dispersal (McHatton, 1957; Romberg, 1968; Sargent, 1918). Their arrival to North America in 12,500 to $19,000 \mathrm{BP}$ (Hadingham, 2004) dates back to the last ice age (13,000 BP) and coincides with or precedes the northern migration of hickories. However, there probably would have been little incentive to propagate a species that was already in abundant supply, in contrast to scarce fruit tree species (Williams, 2002). Regardless, Indians stored pecans as a food source (True, 1917). Seeds may have been inadvertently disseminated into new areas as Indians traveled to establish campsites or villages on loamy, well drained river bottoms. The wideranging Spanish explorers may have distributed pecan into the fringe areas of the southwestern U.S. (Hester, 1981) and Mexico.

Blue jays are the major avian dispersal agent of pecan seed. Dispersal is significant by crows (Corvus brachyrhynchos) along with red-bellied (Centrus carolinus) and red-headed (Melanerpes erythrocephalus) woodpeckers (Batcheller, 1980; Leppla, 1980). Blue jays prefer small nuts (Hall and Smith, 1984; Hinrichs, 1967; Leppla, 1980). Crows prefer larger nuts (Leppla, 1980; Murray, 1975), especially with a thin shell (Lemaire, 1950). However, crows freely feed on small nuts if large nuts are not available (Leppla, 1980). The differential size preference between the blue jays and crows is correlated with differences in beak length. Beaks of crows are about 2.5 times longer than blue jays (Arnold, 1938; Lemaire, 1950), which enhances their ability to hold larger nuts. Blue jays carry nuts up to $500 \mathrm{~m}$ (Batcheller, 1980) and crows at up to $3.2 \mathrm{~km}$ (M. Bulger, personal communication), implicating them as significant, long distance dispersal agents.

The eastern fox squirrel (Scriurus niger) is the majormammalian dispersal species (Leppla, 1980). The evolution of squirrels coincided with that of hickory nuts (Romer, 1966) suggesting that they have been a significant dispersal agent since the early development of Carya. Squirrels can bury nuts at considerable distance from the parent tree (Ridley, 1930). Their dispersal effectiveness is further increased by scatter hoarding (burying small caches at dispersed sites) as op- posed to larder hoarding (storing seeds in large caches) (Stapanian and Smith, 1978).

Although eastern fox squirrels and blue jays are major dispersal agents of pecan seed, a significant question exists as to how efficient their caching of nuts is in disseminating the species. First, caching by blue jays is an instinctive reflex, not a conscious effort to store food for a time of scarcity (Arnold, 1938) as they also store perishable food items (Arnold, 1938; Laskey, 1942). Second, blue jay caching of pecan may occur in low frequency (Batcheller, 1980), but work summarized by Vander Wall(1990) refutes this. Third, blue jays and eastern fox squirrels often cache pecan seed in unfavorable sites for pecan tree establishment. For example, eastern fox squirrel prime habitats in Oklahoma are pecan forests and adjacent upland oak forest (Chesemore, 1975). Seeds cached in the pecan forest have a reproductive chance but not those cached in the oak forest. Fourth, squirrels can recover and consume up to $99 \%$ of the nuts they bury (Cahalane, 1942), thus further reducing reproductive chance. Recovery efficiency of blue jays is less (Laskey, 1943). Fifth, there appears to be no documentation that hickories establish from animal caches (Vander Wall, 1990).

Within the pecan forest, low seed production years or "off" years are reproductive negatives as predation can be virtually complete. Predation completion may be enhanced by the preference of squirrels, crows, and blue jays for pecans and other Carya spp. over acorns (Barber, 1954; Lemaire, 1950; Lewis, 1982; Murray, 1975; Nixon et al., 1975). In contrast, during an "on" year, predator satiation occurs and nuts are left on the floor of the pecan forest. Thus, "on" years increase the chance for perpetuation of the pecan forest via sib/half sib seedlings and for seed dispersal in general. Pecan forest perpetuation by sib/half sib seedlings following predator satiation is supported by genetic variability in pecan (Adams, 1976). Trees growing within stands, though genetically variable individually, exhibited a closer relationship to other trees in that stand (inbreeding) than to trees in stands from 0.8 to $8 \mathrm{~km}$ apart.

Unsuccessful attempts to transfer nuts (i.e., transport failure) may be the major means of disseminating pecan into unpopulated but preferred sites of first bottoms, e.g., new sites formed by shifting river courses. The concept of transport failure is supported by long-term observations of a pasture adjacent to a pecan orchard in Georgia. Over time, pecan seedlings established in the areas of the pasture corresponding to the birds' flight lane. This relationship suggests birds accidentally dropped the nut because of being too large for the bird to firmly grasp and/or inter- and intraspecific aggression of woodpeckers (Batcheller, 1980, Kilham, 1963 ), blue jays, and crows. Outbound crows may drop a nut on approaching an aggressive inbound crow, or answering a passing crow's call, and then immediately return to the orchard for a new nut (E. Palmer, personal communication). Also, the frequent and accidental drop of intact nuts during bird feeding (Arnold, 1938) may be a factor in dissemination. This concept is supported by the frequent occurrence of seedlings growing within fence rows and on the forest edge in Georgia. Accidental drops may be especially significant with blue jays because they prefer to feed from perches (Batcheller, 1980). Large perches, whether limbs, fence posts, etc., are required for blue jays to hold the nut with their feet while cracking the nut. Drops from woodpeckers storage activities are also likely. Woodpeckers store food in natural cavities including crevices, knot holes, loose bark on standing trees, and desiccation cracks in fence posts and utility poles (Kilham, 1963; McRoberts, 1975). Woodpeckers, except for $M$. formicivorus, crack the shell and store bits of kernel (Vander Wall, 1990). Woodpeckers do not hold the nut with their feet while cracking the shell. Instead, they wedge the nut into a crack, such as in fence posts, before cracking the shell. Blue jays (Batcheller, 1980) and woodpeckers (Vander Wall, 1990) harvest nuts directly from the tree and ignore nuts that fall to the ground, suggesting accidental drops from perches are probably left where they fall. However, accidental drops from perches may not totally account for fence row and forest edge pecan seedlings. Crows cache food in dense vegetation (Vander Wall, 1990) and in grass (Conner and Williamson, 1984), both of which are often characteristic of fence rows and forest edges. Transport failure or accidental drops are less probable with squirrels. A squirrel is more likely to hold, rather than release, food in its mouth when frightened or shot during feeding (Baker, 1944).

\section{Selective Pressures for Seed Characteristics}

The tendency for nuts to be predominantly small is enhanced by multiple selection pressures. Blue jays' and squirrels' preference for small nuts (Hall and Smith, 1984; Hinrichs, 1967) increase selection for a smaller size nut. Although crows may prefer the large nuts of cultivars over small nuts of seedlings (Leppla, 1980), they do not prefer exceptionally large nuts, such as 'Mahan' (Murray, 1975). The low dissemination of large nuts, in effect, imposes an upper limit on nut size. A small volume nut is advantageous to species perpetuation because seed development is better for small compared to large volume nuts under stress conditions, such as drought and excessive fruiting (Sparks, 2002b).

Selective pressures exist for shell thickness. Thinned-shell nuts (high percentage kernel) are more susceptibility to bird predation, especially for early maturing genotypes (Hinrichs, 1967). Early maturing, thin-shelled nuts tend to be consumed on site (Hall and Smith, 1984; Leppla, 1980), biasing selection against thin shells. Thus, a thick shell indirectly increases the chance for species survival. The low frequency of thin shell nuts (high percentage kernel) may also be partly due to the higher energy requirement for kernel development, especially for large nuts as discussed previously. However, thin-shelled nuts are more likely than thick-shelled nuts to rot when planted in the nursery (P.J. Conner, personal communication) suggesting that a thick shell better protects the seed from pathogenic organisms. 
The predominance of small seeds with a low percentage kernel might be considered a disadvantage in species perpetuation because of reduced energy content relative to large nuts. Height offirstyear seedlings, however, is weakly coordinated with seed size across stands and families and is three (Harris and Tauer, 1987) to five (Adams, 1976) times more dependent on other genetic factors. The correlation was weak in spite of the wide variance in seed weight in the studies, 2.0 to $6.3 \mathrm{~g}$ and from 1.4 to 5.5 $\mathrm{g}$, respectively. Similarly, first year height is weakly correlated with mean percentage kernel (20\% to 60\%) across seedling families (Grauke, 1990). Across stands and families, inbreeding depression of vigor may be more important than seed size (Harris and Tauer, 1987). Regardless, seedlings from genotypic small seed may have a shorter dependence period on the kernel for nutrient reserves; that is, photosynthetic competency may develop earlier than seedlings from genotypic large nuts. Alternatively, significant energy is available for seedling establishment regardless of nut size, but energy for regeneration of a damaged epicotyl may be more limited.

The strongest correlation between first year growth and seed weight occurred with 'Western Schley' seeds (Hinrichs, 1965). Growth was suppressed for seed weighing $4.5 \mathrm{~g}$ or less, compared to seed weighing 5.5 to $8.4 \mathrm{~g}$. However, whether or not growth suppression was due to poor kernel development and, thus, less nut weight or, from small but well filled nuts is unknown.

Shape is another seed characteristic likely selected as a result of bird predation. Most nuts are some variation of oblong. Very few are round (Sparks, 1992a). Big, round nuts are difficult for birds to carry in their beaks as indicated by beak marks on nuts left on the ground, 'Shoshoni' being an excellent example. Thus, the probability of a round, big nut being disseminated is greatly diminished. Cross-sectional shape [round, oval, oblate, and oblong (Sparks, 1992a)] may affect the ease of dissemination of larger nuts. Desirable nuts with an oval cross-section are preferred by crows 3.5 to 1 over the smaller 'Stuart', which has a round cross section (Murray, 1975). 'Forkert', 'Pawnee', and 'Schley' nuts with distinctly oblong cross sections are highly preferred by crows. Apparently, nuts with a cross section less than round are easier to grip. Cross-sectional shape appears less important with small nuts (Murray, 1975), probably because small is easier to grip and carry in the mouth. Blue jays may carry three small nuts simultaneously, one in the beak and two in the upper portion of the esophagus (Batcheller, 1980).

\section{Adaptability to Pests}

Co-evolution apparently occurred between pecan within its native habitat and the arthropod and microbial pests attacking the plant, with the exception of cotton root rot [Phymatotrichum omnivorum (Shear) Duggar] (Harris, 1983; Reid, 1997). Cotton root rot occurs in orchards planted in old fields in warm climates with high $\mathrm{pH}$ soils (Sparks, 2000b). The disease is not a problem on adjacent native pecan sites, presum- ably due to a higher soil organic matter which inhibits the fungus (Streets and Bloss, 1973). Thus, pests do not limit pecan perpetuation within its native habitat. Successful coexistence implies mechanisms that allow pecan and its pests to survive.

There are five basic defensive mechanisms against arthropod attack; escape in space, escape in time, biological associations, confrontation, and accommodation (Harris, 1983). Confrontation and accommodation also apply to microbial pests. Escape in space is an important defense mechanismagainst pecan twig phylloxera ( Phylloxera devastatrix Pergande). Many genotypes are immune to this insect (Calcote and Hyder, 1980; Harris, 1982). Consequently, in native stands, the insect must expend considerable energy and time to find an alternative tree to infest. Escape in time is the major defense mechanism against fruit-feeding arthropods (Harris, 1983). Escape in time occurs within the growing season and among years. Pecan weevil [(Curculio caryae (Horn)], the most important fruit-feeder in commercial groves and orchards, is a good example. Pecan weevil successfully oviposit in fruits only between the gel stage and shuck split (Harris and Ring, 1979). Generally, weevils emerge from the soil about the time the gel stage begins in the earliest maturing genotypes. Ovipositing females live for only a few weeks (Harris, 1983), hence late maturing genotypes escape significant damage (Calcote and Hyder, 1981). Escape in time among years is related to irregular fruiting. During "off" years, most nuts are lost to pecan weevil(M.W.Smith, personal communication). The net result is to starve and limit reproduction of the population during "off" years and then quickly satiate the small population during the "on" year. Here, irregular bearing is a survival advantage to pecan, that is, the "off" year reduces the insect population to a level that, in effect, allows a high percentage of the seed to mature during the "on" year. The same mechanism is operative with pecan nut casebearer. Percentage fruit damage is less during "on" than during "off" years, leaving ample seed for propagation (Sparks, unpublished data). The mechanism is not limited to arthropods. Squirrel populations decrease during “off" years (Nixon et al., 1975) resulting in the small population being quickly satiated during the "on" year.

Biological associations beneficial to pecan consist mainly of parasites, diseases, and predators that attack pecan insects. Biological associations are especially significant in the control of pecan leaf scorch mites (Eotetranycus hicoriae McGregor), black pecan aphids [Melanocallis caryella (Fitch)], black margined aphids [Monellia caryella (Fitch)], yellow pecan aphids (Monelliopsis pecanis Bissel), pecan serpentine leafminer [Stigmellajuglandifoliella (Clemens)], and pecan upper surface blotchy leafminer(Lithocolletis caryaefoliella Clemens) (Harris, 1983). Mostyears, associations are very effective but, periodically, the associations break down and epidemic outbreaks occur over wide geographic areas. Epidemics occurred with yellow and black margined aphids in 1984 and 1985 (Sparks, 1991b), blotchy leafminer in southwest Texas in 1986 (personal observation), and wal- nut caterpillar (Datana integerrima Grote and Robinson) in 1973 in Texas (Harris, 1982). All trees are more or less equally stressed during these outbreaks and the competitive advantage among genotypes remains similar.

Confrontation is common. Pests like pecan scab [Cladosporium caryigenum (Ell. \& Langl.) Gottwald] and pecan phylloxera are genotypic specific. Thus, where trees with a certain genetic profile may succumb, the species as a whole is protected from an epidemic (Harris, 1983). Scab on the fruit of a highly susceptible genotype prevents viable seed production during highly infectious years, thus reducing a genetic predisposition to scab to potential offspring. Furthermore, severe scab dwarfs tree growth by killing a portion of the expanding shoots which over time gradually suppress tree height to a less competitive position in the forest canopy. If the scab mutates, only a small portion of the diverse seedling population becomes severely infected and natural selection persists. Similarly, a genotype highly susceptible to southern pecan leaf phylloxera [Phylloxera russellae Stoetzel] has less survival chance. This insect induces severe premature, late summer defoliation. Reproductive opportunity is reduced for the genotype by producing poor quality seed in the current year and diminishing tree vigor and seed production the following year.

Accommodation of arthropods operates when the tree produces more of a plant part than it needs to remain biologically viable (Harris, 1983). The lost plant part has a minimal impact on the tree's ability to compete with other pecan trees in the forest. Accommodation occurs mainly for leaves, e.g., fall webworm [Hyhantria cunea (Drury)] and brown leaf spot (Cercospora fusca Rands) but to a limited extent for fruit, e.g., southern green stink bug [Nezara viridula (Linnaeus)].

\section{Relationships to Pecan Culture}

Tree development. Small seeds, e.g., 'Curtis,' are traditionally planted in most nurseries (Gast and Overcash, 1980), presumably because of the better seed quality characteristic of small nuts (Sparks, 2002b) and low cost per seed. As with small seeded native genotypes (Adams, 1976), there is not a strong relationship between increased seedling vigor and increased seed size of cultivars (Grauke and Pratt, 1985; Reighard, 1990). In nurseries, dieback of the emerging epicotyl from sensitivity to high soil surface temperatures is circumvented by planting the nuts before March (southeastern U.S.) so that germination occurs before the onset of excessive soil temperature (Demaree, 1927). Excessive soil temperature may be circumvented in later plantings by overhead irrigation $\left(20 \mathrm{~mm} \cdot \mathrm{ha}^{-1}\right)$ during noon, or by shading the soils surface by growth of native grasses and weeds within the row for the first year. Lag growth of the top occurs during the first season and continues into the second and sometimes third year in most nurseries as in nature. Height is inherently fixed during the first season. However, height growth can be rapid after the first year and may reach 2 $\mathrm{m}$ by the end of the second (personal observation) or third (Reighard, 1990) growing season 
by optimizing soil moisture, sunlight exposure, and nutrition, as well as, controlling pecan bud moth [Gretchena bolliana (Singlerland)] and other herbivores. These results suggest growing conditions following seed planting are more important than seed genotype.

The axillary meristems on the root remain viable for many years (Romberg, 1944) and are the source of seedling trees in orchards following premature death of cultivars produced by grafting scions onto seedling roots. Premature death is usually caused by cold injury. Seedlings are especially prevalent in orchards established in the early 1900 s when nursery propagation was solely by root grafting (Sparks, 1992a).

Budding cultivars onto juvenile trunks is advantageous in orchard establishment because the juvenile seedling trunk imparts cold resistance to the cultivar (Guengerich et al., 1967; Sparks and Payne, 1977). Most nurserymen propagate solely by root grafts or else by budding the larger seedlings in the summer and root grafting the smaller seedlings in the following winter, allowing a once-over tree harvest. Thus, planted trees are often root grafted or a mixture of budded and root grafted. Considering the potential for cold injury in new plantings (Sparks and Payne, 1978), propagation should be solely by budding. In nurseries with dual propagation methods, grafted trees are often poorer quality than budded trees because the former is shorter and, thus, have less sunlight exposure, reflecting pecan's shade intolerance.

The pattern of root development described for native seedlings is the same for pecan transplanted from the nursery to the orchard. Although, the taproot is usually severed during digging from the nursery, single or multiple taproots are immediately regenerated following transplanting. Roots grew to a depth of at least $4.3 \mathrm{~m}$ by end of the second growing season in an orchard with deep soil in southwest Texas. However, rooting depth is greatly abbreviated in shallow soils, as in the southeastern U.S., with a resulting shallow root system (Woodroof and Woodroof, 1934).

Responsiveness of the humus-topsoil roots to soil moisture is evident in sod-culture orchards irrigated by microjets or emitters. The roots develop to an unusual degree and form a mat within the wetted area. Development of humus-topsoil roots is also accelerated in sprinkler-irrigated orchards but to a lesser degree. Ferti-irrigation of small areas of the orchard floor via drip and microjet is successful even for very large trees (20 or fewer trees per ha) which lends supports for the importance of humus-topsoil roots in nutrient uptake. The apparent significance of these roots in aeration is evident in trees set too deep at planting. In Georgia, young $(\leq 13$ years old) trees set too deep died back or died in 2004 following the very wet 2003 . The same occurred with trees in which brace roots failed to develop and lateral root development from the taproot was restricted to a soil depth of 40 $\mathrm{cm}$ or greater (personal observation). In this case, the trees were set correctly.

The significance of the humus-topsoil roots in zinc nutrition is evident in orchards in the southeastern U.S. as under native conditions. Zinc deficiency can be induced if the sod is destroyed as during preparation of the orchard floor for mechanical harvest. Once the sod is reestablished, $\mathrm{Zn}$ deficiency is corrected. Widespread $\mathrm{Zn}$ deficiency in Georgia during the 1920s (Sparks, 1987) was associated with or else enhanced by the common practice of interplanting pecans with corn, cotton, or other crops that required frequent cultivation (Alben et al., 1932; Demaree, 1933). Pecan trees planted on calcareous soils and clean cultivated are very susceptible to zinc deficiency, however, if soil organic matter is replenished by long-termed sod culture (Hunter, 1950), zinc deficiency is not a problem (Sparks, 2004a).

As with juvenile seedlings, phototropic response from an under story position occurs with cultivars. During the 1970s, skips were replanted in many Georgia orchards established in the 1920s. Today, these replants are equal or near the height of the older trees. During the same era, skips in overcrowded orchards were also planted. Although many of the trees persisted in an arrested stage for years, they eventually died of shading. If, however, a light gap was created by removal of an adjacent, large tree, the arrested tree grew vigorous as occurs in a native pecan forest. Pecan shade intolerance is also vividly illustrated in crowded orchards as lower limbs gradually die leaving only the uppermost canopy. Pecan's shade intolerance first became evident as a significant cultural problem shortly after establishment of Georgia's industry in the 1920 s when many orchards were planted at a $4.6 \times 9.1 \mathrm{~m}$ spacing. Tree thinning was required before the trees bore profitably (Reed, 1926). The same mistake was repeated in late 1960 s to early 1970 s.

Training orchard trees based on natural tree form, i.e., a central leader with scaffold limbs having smaller diameters than the trunk (Sparks, 1981), is highly successful. Strong tree structure is paramount because of the large tree size and the massive weight of the leaves and fruit that is often concentrated on the distal end of the branches. Good but not excellent crotch angles may support the limb for many years but they eventually split with increasing tree size. Crotch split in 'Pabst', one of the most vigorous cultivars (Sparks, 1992a), may not occur until the tree is 80 or more years old.

Soil moisture. Pecan's sensitivity to soil moisture is strikingly evident in Georgia pecan orchards. Nonirrigated orchards on moderately well drained soils are more productive (Middleton et al., 1968) and the trees are larger than those on adjacent well drained soils. Moderately well drained soils are characterized by a high water table in the spring (Pilkinton et al., 1974). Once these areas were sprinkler irrigated, tree vigor and productivity decreased sharply and, in severe cases, tree death occurred. Meanwhile, production on adjacent, irrigated, well drained soil increased. The excessive moisture problem was solved by delaying irrigation until after the water table dropped or by installing underground drainage systems. Tree vigor and productivity were restored.

Localized topographical depressions commonly occur in orchards in the Albany, Ga., area. Under nonirrigated conditions, trees in the depressions benefit from rain runoff from the surrounding slopes and are larger and more productive than trees on the adjacent slopes. This observation was the impetus for irrigating pecan orchards in the Albany area long before irrigation was proven beneficial for pecan (Heaton et al., 1982; Daniell, 1982; Worley, 1982). Irrigation decreased tree vigor and productivity in topographical depressions similar to the aforementioned situation. The problem was circumvented by installing cut off valves on irrigation risers on the slope, thus reducing water accumulation in the depressions. In old orchards in southwest Georgia, the aftermath of historically excessive soil moisture is widespread on the Grady soil series. Grady soil is poorly to very poorly drained due to slow interval drainage of a heavy clay which is compounded by being situated in saucer-shaped depressions (Pilkinton et al., 1974). Tree rows were planted continuous without regard to changing soil types in orchards established in the early 1920 s. Trees planted on Grady and other poorly drained soils were eventually lost from either windthrow due to limited and shallow rooting or gradual declined from waterlogging. Replanting these areas and planting similar areas in new orchards in the 1970s was equally unsuccessful.

Benefits resulting from a high water table overlain by a well drained soil is demonstrated by tree growth in Waycross and Albany, Ga. (personal observation). 'Stuart' trees in Waycross, where the water table is about $2 \mathrm{~m}$ below the soil surface (somewhat analogous to native pecan soils), are much larger than in Albany, where the water table is below the soil's parent material and, thus, beyond the reach of roots. The Albany trees are smaller even though they are about 25 years older. The same promotive effect is commonly observed on well drained local alluvial land near streams. On the other extreme, trees on sandy soils are smaller and less productive than soils on adjacent soil with a higher clay content. Installation of higher volume irrigation nozzles on the sandy soils or longer irrigation time tends to alleviate the problem. Pecan's hypersensitivity to water logging near budbreak (Smith and Bourne, 1989) is reflected in the widespread occurrence of iron deficiency in young trees following excessive irrigation of calcareous soils (Sparks, 2000b). The problem is prevented by allowing the soil to drain to field capacity before budbreak and delaying further irrigation until after shoot elongation. Once humus-topsoil roots are established, iron deficiency is a spotty and infrequent occurrence. Sensitivity to waterlogging near budbreak is also often expressed in first year transplants regardless of geographical region. Leaves abscise followed by varying degrees of shoot dieback. The disorder invariably occurs during wet springs or when excessive water is applied either manually or by the common practice of placing the irrigation emitter directly over the transplant hole. The disorder is prevented in normal springs by probing the soil for moisture and manually watering as needed or, in the case of drip irrigation, by placing the emitter about $1 \mathrm{~m}$ from the tree trunk. Once roots develop outside the transplant hole, dieback is not a problem. In Georgia, years of excessive rainfall during May to July, as in the very wet 
1989 and 1991, are followed the next year by reduced production (Sparks, 1996), especially in 'Stuart' (Sparks, 1992b). These examples demonstrate that pecan's high water requirement and its sensitivity to excessive water are major considerations in its culture.

In Georgia pecan orchards, roots are most numerous within the top 45 to $60 \mathrm{~cm}$ of soil (White and Edwards, 1978; Woodroof, 1933; Woodroof and Woodroof, 1934; Worley et al., 1974) although there is some variation with soil type. Dramatic results occur from irrigation (Daniell, 1982; Heaton et al., 1982; Worley, 1982) in spite of high rainfall in this area because of the abbreviated root system enforced by shallow soils and the low available water capacity of the soils. Also, the shallow roots cause mature trees to be susceptible to windthrow, especially cultivars with dense foliage, i.e., 'Schley' (Sparks and Payne, 1986) or with a vigorous spreading canopy, i.e., 'Cape Fear' (Sparks, 1992a). Windthrow is severe during tornadoes and hurricanes as occurred during hurricanes Elena, Frederic (Sparks, 1992a), Danny (Nesbitt, 1997), Frances, Ivan, and Jeanne. Trees with brace roots positioned symmetrically around the trunk are less likely to uproot than those with asymmetrically positioned brace roots, as evident during Frances, Ivan, and Jeanne. Wind resistance is influenced by setting depth at planting as was also evident during the hurricanes. Trees with $\$ 6.0 \mathrm{~cm}$ or more of the trunk set below the soil surface did not form brace roots and were subjected to windthrow (Sparks, 2005).

Reproductive stress. Selection and breeding precocious cultivars have resulted in severe problems, mainly, poornutquality, enhancement of irregular fruiting, tree dieback (Sparks, 1992a, 2000b), premature defoliation (Sparks, 1977), and increased susceptibly to freeze injury (Smith et al, 1993b). All problems are accentuated for cultivars producing a large nut, i.e., 'Mohawk', 'Mahan,' and 'Success', or for extremely precocious cultivars even with moderate-sized nuts, i.e., 'Cherokee', 'Cheyenne', and 'Chickasaw'. Cultivars with small nuts, i.e., 'Elliott', 'Candy', and 'Farley' usually have fewer nut quality problems unless they are extremely precocious as in 'Moore'(Hunter, 1950). Today, mechanical fruit thinning can solve most of the problems associated with excessively fruiting (Reid et al., 1993; Smith and Gallott, 1990; Smith et al., 1993b). The pioneering research of these workers produced a practical solution to the long-standing irregular bearing problem in pecan. Mechanical fruit thinning allows annual nut production (Sparks, 2001), barring adverse weather (Sparks, 1996; 1997b).

Fruit inhibition offloral induction is apparent in 'Desirable'. 'Desirable' is the most consistent annual producing pecan cultivar. This cultivar self thins its fruit during the second drop (Sparks and Madden, 1985), which occurs before floral induction (Amling and Amling, 1983). Fruit inhibition of floral induction is also supported by mechanical fruit thinning studies (Reid et al., 1993). Fruit thinning is mainly effective if used before floral induction.

As discussed earlier, rainfall and fruit growth in the native pecan area coincide in a manner that promotes good nut quality. Low rainfall during the nut sizing period, July and August (Sparks, 2001a), ensures a small volume nut which is easier to fill (Sparks, 2002b). Well-developed kernels are further promoted by an increase in rainfall during the September nut filling period. In contrast, in Georgia, the high rainfall during the 20 June to 15 Aug. nut-sizing period maximizes nut volume. Poor filling of the large nut becomes a major threat because rainfall begins to decline in midAugust and continues through the September kernel filling period and through the shuck dehiscence period in early to late October (Sparks, 2001). Emphasis on irrigation during September(Sparks, 1992a, 1995a, 1997a, 2001) has resulted in irrigation at this time becoming a standard practice, greatly improving nut quality and shuck dehiscence.

In an attempt to mimic soil moisture conditions in native areas, that is, minimize nut volume, deficit irrigation during fruit sizing was recommended for drip-irrigated orchards in Georgia followed by maximum irrigation during kernel development (Sparks, 1995b, 1995 c, 2001). Minimizing nut volume in drip irrigated orchards is of paramount importance in that most drip systems in Georgia are designed to deliver only half of the water required by the crop (Sparks, 2001). Consequently, irrigation volume is insufficient to fill a large nut if September is dry. Growers' results have been positive. Recently, deficit irrigation has been used to a limited extent in sprinkler-irrigated orchards because of better quality obtained with a smaller nut, especially when fruit set is heavy.

Georgia's pecan industry is based on the early market (gift packs, Thanksgiving, and Christmas trade) in which a premium price is paid for nuts with large, intact kernels, termed whole halves. Whether or not large kernels are preferred by the consumer, or one historically imposed by the industry, is an important question, especially since small nuts generally have superior flavor due to better kernel development. A consumer preference study is needed.

Pests. Irregular bearing is maximized in orchards with a no or marginal culture (Conner and Worley, 2000) or with highly prolific cultivars (Sparks, 1983). When culture is improved, irregular bearing in orchards and in groves is minimized as production during the "off" year is increased (Conner and Worley, 2000; Reid, 1985; Sparks, 1983). The result of annual production is that the mechanism for escaping fruit feeding insects in time among years is essentially eliminated, i.e., there are insufficient barren years to starve out and reduce insect populations. Thus, they quickly increase to very high populations. In an orchard, where genetical diversity is drastically reduced by planting only a few cultivars, escaping weevils in time within the same year is minimized unless the orchard contains late maturing cultivars, i.e., 'Curtis' and 'Summer'.

Annual production and/or minimal genetic diversity increase the need for pesticides. Pesticides targeted against specific pests have a major side effect, that is, biological associations usually undergo major disruption, especially the one controlling the yellow aphid complex.
Pesticides directed against these aphids or against other insect pests, such as pecan weevil and hickory shuckworm [(Laspeyresia caryana (Fitch)], are almostalways followed by an aphid resurgence (Dutcher, 1983; Dutcher and Payne, 1983). Continuous resurgence results in heavy sooty mold (Polyhaeton sp.) accumulation which blocks sunlight from the leaf (Tedders and Smith, 1976). The subsequent reduction in photosynthesis was proposed to reduce nut production(Sparks, 1991b) more than herbivory losses (Wood and Tedders, 1982; Tedders and Wood, 1985 ) due to aphid feeding. Insecticide application, therefore, indirectly increased sooty mold. Renewed interest in earlier integrated pest management programs (Dutcher, 1981; Harris, 1985) led to the practice of not spraying to control aphids which minimized sooty mold accumulation. Today, the yellow aphid resurgence problem can be prevented by a number of aphidicides (Dutcher, 2005). During the late 1960s, black aphids, if they occurred at all, were limited primarily to September. Today, they are a problem in the spring and as well as in the fall (Ellis, 1999), indicating an important biological association may have been disrupted. The same appears to have occurred with pecan leaf scorch mite [Eotetranychus hicoriae (McGregor)].

Accommodation, or acceptable loss of a plant part or product, is used by Oklahoma growers in pecan nut casebearer management. Pistillate flower production is evaluated shortly after pistillate anthesis. If fruit set is judged to be excessive, pesticides are not applied against nut casebearer and the insect is allowed to thin the fruit. Otherwise, a spray program is initiated (M.W. Smith, personal communication). Accommodation is used when yellow and black margined aphid populations are allowed to increase to excessive levels that result in a subsequent rapid decline, termed a crash. Limited accommodation is allowed when thresholds or action levels are established forpecan arthropods (Harris, 1985). Spittlebug (Castoptera achatina Germar), which is often targeted for pesticides, is a good candidate for accommodation. The insect does not induce fruit loss (D. Sparks, unpublished data), as assumed (Payne et al., 1979). Confrontation as a defense mechanism against pests has little value in pecan orchards as orchards are not self renewable.

The advent of mechanical harvesting in Georgia in the early 1972 s and the concomitant emphasis on early and rapid harvest for the profitable, early market has inadvertently reduced pecan weevil populations. The weevilinfested nut is removed from the orchard before the larva exits the nut and burrows into the soil, thus, gradually reducing the population in spite of an ample food supply.

Abandon orchard decline. Widespread premature defoliation from leaffeeders and diseases commonly occurs in abandoned orchards in the southeastern U.S. because the large genetic diversity found in pecans's native habit does not exist in orchards. Premature defoliation suppresses tree growth thus enhancing supplanting of the orchard with native tree species. Supplantion is accelerated when premature defoliation occurs during an "on" year. Dieback and/or tree death follow the next season (Wood and Reilly, 
2001) and can be especially severe if premature defoliation and the "on" year coincides with a drought year. Drought severity is intensified by an abbreviated root system induced by shallow soils. Once the tree is subjected to prolonged stress, the roots are susceptible to tile-horned prionus [Prionus imbricornis (L.)] (Craighead, 1942; Eyer, 1942) whose natural host is oaks. The root-boring larvae can destroy $75 \%$ to $90 \%$ of the root system resulting in tree death (Sparks et al., 1974). In an abandoned orchard, tree replacement does not occur as seedlings from nuts germinating on the orchard floor are apparently shaded out by native tree species and/or fail to successfully compete for limited soil moisture in the shallow soils. Regardless, with time, the orchard may be totally supplanted by native trees with decreased water requirement and fewer pest problems. Nevertheless, a few very large pecan trees exist outside orchard sites in Georgia. These trees are restricted to homestead sites, crop land, and pastures, where competition is somewhat controlled, or to well drained soil with a high water table.

Stretching the limits. A surge in pecan plantings began in the late 1970s in the warm, Crystal City area of Texas which is within the southwestern limit of pecan's native range. Commercially, the area was attractive because nut maturity is earlier than any other area in the United States (Sparks, 2000b). Today, most of these orchards have been abandoned from lack of attention to cotton root rot and because of vivipary. Vivipary was accentuated by predominantly planting 'Wichita' which is highly susceptible to the problem (Sparks, 2002c). 'Wichita' fruits excessively, a stress that can induces vivipary before the nut is mature enough to harvest. Vivipary is minimized by mechanical fruit thinning and by early harvest (Sparks, 2000b; Sparks et al., 1995). If not harvested early, the nuts continue to germinate (Finch, 1937) regardless of crop load. The Crystal City experience stands as an expensive reminder of the risk of planting pecan in an area that is marginally suited for the crop. On the other climatic extreme, much effort has been expended in an attempt to find pecan genotypes suited to areas beyond pecan's northern range (Bernard, 1980; Campbell, 1976, 1991, 1995; Dabb, 1979). The climate is too cool to mature the crop and, if a suitable cultivar is selected, production will be low due to the small nut size and low percentage kernel associated with short-season pecans (Campbell, 1997).

\section{Conclusions}

Pecan is well adapted to a native range encompassing a wide variance in climate. Effects of differences in rainfall are minimal due to pecan's riverine habitat and a deep and phreatophytic rooting habit. Pecan's shade intolerance is minimized by exacting site requirements which excludes pecan's more vigorous sympatric species. Natural selection from an apparent wide genetic diversity has resulted in genotypes that have adapted to a wide temperature range and accompanying growing season length. Reproductive stress, resulting from the high lipid content in the seed, is minimized by a long juvenile period, small nuts with low percentage kernel, and "off" production years. Predators indirectly enhance propagation by small seeds. Perpetuation of pecan forests appears to be mainly from sib/half sib seedlings following predator satiation while dissemination into new areas is mainly by predators. Pecan successfully co-exists with its pests mainly by four mechanisms, escape in time, biological associations, accommodation, and confrontation. The mechanisms governing pecan distribution in its native habitat have direct implications to pecan culture.

\section{Literature Cited}

Acuna-Maldconado, L.E., M.W. Smith, N.O. Maness, B.S. Cheary, and B.L. Carroll. 2003. Influence of nitrogen application time on nitrogen absorption, partitioning, and yield of pecan. J. Amer. Soc. Hort. Sci. 128:155-162.

Adams, J.C. 1976. A study of genetic variability in wild populations of pecan (Carya illinoensis (Wangenh.) K. Koch). PhD diss. La. State Univ., Baton Rouge.

Alben, A.O. 1946. Nitrogen deficiency of pecans in the spring of 1946. Proc. Texas Pecan Growers Assn. 25:24-27.

Alben, A.O. 1955. Studies on relation of drought injury of pecan trees to soil textures and profiles. Proc. Texas Pecan Growers Assn. 34:32-38.

Alben,A.O. 1958. Waterlogging of subsoil associated with scorching and defoliation of Stuart pecan trees. Proc. Amer. Soc. Hort. Sci. 72:219-233.

Alben,A.O., J.R. Cole, and R.D. Lewis. 1932. Chemical treatment of pecan rosette. Phytopathology 22:595-601

Amling, H.J. and D.A. Amling. 1983. Physiological differentiation of pistillate flowers of pecan and cold requirements for their initiation. J. Amer. Soc. Hort. Sci. 108:195-198.

Arnold, J.R. 1938. The systematic position and natural history of the northern blue jay (Cyanocitta cristata bromia Oberholser). PhD diss. Cornell Univ., Ithaca, N.Y.

Atkinson, D. 1980. The distribution and effectiveness of the roots of tree crops, p. 424-490. In J. Janick (ed.). Horticultural reviews. vol. 2. AVI, Westport, Conn.

Avants, J.K. and R. Pressey. 1972. Uses for pecan shells. Pecan Quart. 6(4):19.

Baker, F.S. 1950. Principles of silviculture. McGrawHill, New York.

Baker, F.E. 1979. Soil survey of Bastrop County, Texas. U.S. Dept. Agr. Soil Conservation Serv., Wash. D.C.

Baker, R.H. 1944. An ecological study of the tree squirrels in eastern Texas. J. Mammal. 25:8-24.

Barber, H.L. 1954. Gray and fox squirrel food habits investigations. S.E. Game Fish Comm. 8:92-94.

Barnett, R.J. 1977. The effect of burial by squirrels on germination and survival of oaks and hickory nuts. Amer. Midl. Nat. 98:319-330.

Batcheller. G.R. 1980. The ecology and behavior of blue jays in Oklahoma pecan orchards. MS thesis. Okla. State Univ., Stillwater.

Bernard, H. 1980. The nut trees of Quebec, native and introduced. Annu. Rpt. N. Nut Growers Assn. 71:21-25.

Bettis, III, E.A., R.G. Baker, B.K. Nations, and D.W. Benn. 1990. Early Holocene pecan Carya illinoensis, in the Mississippi River Valley near Muscatine, Iowa. Quaternary Res. 33:102-107.

Blum, E.L. 1982. Soil survey of Kimble, Texas. U.S. Dept. Agr. Soil Conservation Serv., Wash., D.C.
Boisen, A.T. and J.S. Newlin. 1910. The commercial hickories. U.S. Dept. Agr. Forest Serv. Bul. 80.

Cahalane, V.H. 1942. Caching and recovery of food by the western fox squirrel. J. Wildl. Mgt. 6:338-352.

Calcote, V.R. and D.E. Hyder. 1980. Pecan cultivars tested for resistance to pecan phylloxera. J. Ga. Entomol. Soc. 15:428-431.

Calcote, V.R. and D.E. Hyder. 1981. Pecan weevil preference for various pecan cultivars. J. Econ. Entomol. 74:223-226.

Campbell, R.D. 1976. The great northern pecans. Annu. Rpt. N. Nut Growers Assn. 67:26-28.

Campbell, R.D. 1991. Moving ahead with northern pecans in Ontario. Annu. Rpt. N. Nut Growers Assn. 82:94-95.

Campbell, R.D. 1995. The best pecans for Ontario. Annu. Rpt. N. Nut Growers Assn. 86:78-79.

Campbell, R.D. 1997. Kernel quality in northern pecans. Annu. Rpt. N. Nut Growers Assn. 88:69-70.

Chesemore, D.L. 1975. Ecology of fox and gray squirrels (Sciurus niger and Sciurus carolinensis) in Oklahoma. PhD diss. Okla. State Univ., Stillwater.

Ching, T.M. 1963. Fat utilization in germinating Douglas fir seed. Plant Physiol. 38:722-728.

Ching, T.M. 1966. Compositional changes of Douglas fir seeds during germination. Plant Physiol. 41:1313-1319.

Chung, C.S., M.K. Harris, and J.B. Storey. 1995. Masting in pecan. J. Amer. Soc. Hort. Sci. 120:386-393.

Cochran, G.C. 1930. Winter injury of pecans. Proc. Natl. Pecan Assn. Bul. 29:78-80.

Coile, T.S. 1937. Distribution of forest tree roots in North Carolina Piedmont soils. J. For. 35:247-257.

Conner, R.N. and J.H. Williamson. 1984. Food storing by American crows. Bul. Tex. Ornithol. Soc. 17:13-14.

Conner, P.J. and R.E. Worley. 2000. Alternate bearing intensity of pecan cultivars. HortScience 35:1067-1069.

Coppock, S. 1981. Pecan nut casebearer control by aerial application. Proc. Okla. Pecan Growers Assn. 51:31-43.

Craighead, F.C. 1942. Insect enemies of eastern forests. U.S. Dept. Agr. Misc. Bul. 657.

Dabb, C. 1979. High altitude nut trees. Annu. Rpt. N. Nut Growers Assn. 70:84-85.

Daniell, J.W. 1982. Supplemental water effects on pecan trees using trickle irrigation. Univ. Ga. Agr. Expt. Sta. Res. Bul. 289.

Davis, J.T. and D. Sparks. 1974. Assimilation and translocation patterns of carbon- 14 in the shoot of fruiting pecan trees, Carya illinoensis Koch. J. Amer. Soc. Hort. Sci. 99:468-480.

Demaree, J.B. 1927. Sand burn of pecan seedlings. Phytopathology 17:657-662.

Demaree, J.B. 1933. Progress of pecan rosette control. Proc. Ga.-Fla. Pecan Growers Assn. 27:38-45.

Dickum, G. 1994. The frigid test. Annu. Rpt. N. Nut Growers Assn. 85:23-24.

Diver, S.G., M.W. Smith, and R.W. McNew. 1984. Influence of fruit development on seasonal elemental concentrations and distribution in fruit and leaves of pecan. Commun. Soil Sci. Plant Anal. 15:619-637.

Dutcher, J.D. 1981. Pecan insect pest control—Crop protection and pest management. Proc. S.E. Pecan Growers Assn. 74:153-157.

Dutcher, J.D. 1983. Carbaryl and aphid resurgence in pecan orchards. J. Ga. Entomol. Soc. 18:492-495.

Dutcher, J.D. 2005. Chemical control of aphids on pecan foliage. Arthropod Mgt. Tests Entomol. 
Soc. Amer. (in press)

Dutcher, J.D. and J.A. Payne. 1983. Impact assessment of carbaryl, dimethoate and dialifor on foliar and nut pests of pecan orchards. J. Georgia Entomol. Soc. 18:496-507.

Ellis, H.C. 1999. Insect and mite monitoring techniques, p. 55-61. In: Pecan industry: Current situation and future challenges. 3rd Natl. Pecan Wkshp. Proc. U.S. Dept. Agr., Agr. Res. Ser. ARS-1998-04.

Eyer, J.R. 1942. Life history and control of the giant apple root borer. N.M. Agr. Expt. Sta. Bul. 295.

Feeny, P.P. 1976. Plant apparency and chemica defense, p. 1-40. In: J. Wallace and R. Maiell (eds.). Recent advances in phytochemistry. vol. 10. Biochemical interactions between plants and insects. Plenum Press, London.

Finch, A.H. 1937. The use of ethylene to improve pecan harvesting. Proc. Amer. Soc. Hort. Sci. 34:74-77.

Finch, A.H. and C.W. Van Horn. 1936. The physiology and control of pecan nut filling and maturity. Ariz. Agr. Expt. Tech. Bul. 62.

Firor, J.W. 1922. Curing the pecan rosette. Proc. S.E. Pecan Growers Assn. 21:45-46.

Flack, J.R. 1970. The spread and domestication of the pecan (Carya illinoensis) in the United States. PhD diss. (diss. abstr. 71-288). Univ. Wis., Madison.

Fowells, H.A. 1965. Silvics of the forest trees of the eastern United States. U.S. Dept. Agr. Hdbk. 271.

Gammon, Jr., N., K.D. Butson, and R.H. Sharpe. 1960. Magnesium content of pecan leaves as influenced by seasonal rainfall and soil type. Soil Crop Sci. Soc. Fla. Proc. 20:154-158.

Gammon, Jr., N., R.G. Leigthy, and R.H. Sharpe. 1963. Estimation of pecan production based on soil site examination and tree size. Proc. Amer. Soc. Hort. Sci. 82:231-236.

Gammon, Jr., N., R.H. Sharpe, and R.G. Leighty. 1955. Relationship between depth to heavytextured subsoil and drought injury to pecans. Soil Sci. Soc. Fla. Proc. 15:31-34.

Gast, R.T. and J.P. Overcash. 1980. Pecan rootstocks and scion cultivars produced by commercial nurseries in the southern United States. Pecan S. 7(2):14-18.

Gemoets, E.E., L.A. Gemoets, T.E. Cannon, R.G. McIntyre. 1976. Cycles in U.S. pecan production 1919-1974 identified by power spectral analysis. J. Amer. Soc. Hort. Sci. 101:550-553.

Grauke, L.J. 1990. The development of selection criteria for pecan seedstocks, p. 125-133. In: B.W Wood and J.A. Payne (eds.). Pecan husbandry: Challenges and opportunities. First national pecan workshop proceedings. U.S. Dept. Agr., Agr. Res. Ser., ARS-96.

Grauke, L.J. 1999. Managing rootstocks, p. 90-101. In: B. McCraw, E.H. Dean, and B.W. Woods (eds.). Pecan industry: Current situation and future challenges. 1st Natl. Pecan Wkshp. Proc. U.S. Dept. Agr., Agr. Res. Ser., ARS, 1998-04.

Grauke, L.J. and J.W. Pratt. 1985. Pecan rootstock research. Proc. S.E. Pecan Growers Assn. 78:123-130.

Greenwade, J.M., R. Schlappi, B. Smith, and W. Crenwelge. 1996. Soil survey of Grimes County, Texas. U.S. Dept. Agr. Natural Resources Conservation Serv., Wash. D.C.

Grime, J.P. and D.W. Jeffery. 1965. Seedling establishment in vertical gradients of sunlight. $\mathrm{J}$. Ecol. 53:621-642.

Guengerich, H.W., A.D. Hibbard, and D.F. Milikan. 1967. The influence of seedling rootstock in the prevention of lethal scion splitting in northern pecans. Annu. Rpt. N. Nut Growers Assn. 58:136-139.
Guidi, R. 1979. Nut tree hardiness in western Massachusetts. Annu. Rpt. N. Nut Growers Assn. 70:58-59.

Hadingham, E. 2004. America's first immigrants. Smithsonian 35(8):91-98.

Hall, T.C. and M.W. Smith. 1984. Wildlife damage ecology in pecan orchards, p. 38-60. In T. Hall (ed.). Wildlife control in Oklahoma pecan orchards. MS thesis. Okla. State Univ., Stillwater.

Harris, M.K. 1982. Genes for resistance to insects in agriculture with a discussion of host-parasite interactions in Carya, p. 72-83. In: H.M. Heybroek, B.R. Stephan, and K. von Weissenberg (eds.). Proceedings 3rd international workshop on the genetics of host-parasite interactions in forests. Wageningen, Netherlands.

Harris, M.K. 1983. Pecan natural defense mechanisms. Annu. Rpt. N. Nut Growers Assn. 74:73-76.

Harris, M.K. 1985. Understanding pecan IPM. Pecan S. 19(6): 13-14

Harris, M.K. 1991. Pecan arthropod management, p. 6-15. In: B. Wood and J.A. Payne (eds.). Pecan husbandry: Challenges and opportunities. 1st Natl. Pecan Wkshp. Proc. U.S. Dept. Agr., Agr Res. Ser., ARS-96.

Harris, M.K. and D.R. Ring. 1979. Biology of pecan weevil from oviposition to larval emergence. Southwest Entomol. 4:73-85.

Harris, K.D. and C.G. Tauer. 1987. Variation among open pollinated provenances of pecan grown in an Oklahoma nursery. Okla. State Univ. Agr. Expt. Sta. Res Rpt. P-892.

Heaton, E.K., J.W. Daniell, and L.C. Moon. 1982. Effect of drip irrigation on pecan quality and relationship of selected quality parameters. J. Food Sci. 47:172-1275.

Hester, T.R. 1981. Late Paleo-Indian occupations at Baker Cave, southwestern Texas. Bul. Texas Archaeol. Soc. 53:101-119.

Hibbard, P.L. 1940. Accumulation of zinc on soil under long-persistent vegetation. Soil Sci. 50:53-55.

Hinrichs, H.A. 1965. Pecan investigations in Oklahoma. Annu. Rpt. N. Nut Growers Assn. 56:44-51.

Hinrichs, H.A. 1967. Evaluation of Oklahoma pecan seedling selections. Annu. Rpt. Northern Nut Growers Assn. 58:50-53.

Holch,A.E. 1931. Development of roots and shoots of certain deciduous tree seedlings in different forest sites. Ecology 12:259-298.

Huckabee, Jr., J.W., D.R. Thompson, J.C. Wyrick, andE.G. Pavlat. 1977. Soil survey of Bell County, Texas. U.S. Dept. Agr. Soil Conservation Ser. Wash., D.C

Hunter, J.H. 1950. Some interrelationships of cultural practices, fertilization, and the production of quality pecan nuts. Proc. S.E. Pecan Growers Assn. 43:78-83

Hunter, J.H. and H.E. Hammar. 1947. The results of applying different fertilizers to the Moore variety of pecan over a ten-year period. Proc. S.E. Pecan Growers Assn. 40:10-32.

Hunter, J.H. and H.E. Hammar. 1948. Nutritional deficiencies associated with poor filling of pecan nuts. Proc. S.E. Pecan Growers Assn. 41:16-33.

Hunter, J.H. and H.E. Hammar. 1952. Influence of cultivation, mulching, and fertilizer on chemical composition of pecan leaves and their relation to yield and quality of nuts. Soil Sci. Proc. 16:346-349.

Hunter, J.H. and H.E. Hammar. 1957. Variation in composition of pecan leaves. Better Crops with Plant Foods 41:18-25.

Jacobson, Jr., G.L., T. Webb, III, and E.C. Grimm. 1987. Patterns and rates of vegetation change during the deglaciation of eastern North America, p. 277-288. In: W.F. Ruddiman and H.E. Wright, Jr. (eds.) North America and adjacent oceans during the last deglaciation. Geol. Soc. Amer. Inc., Boulder, Colo.

Jaynes, R.A. 1976. Northern pecans are for the Midwest. Annu. Rpt. N. Nut Growers Assn. 67:22-25

Keever, C. 1973. Distribution of major forest species in southeastern Pennsylvania. Ecol. Monogr. 43:313-327.

Kerzdorn,A.H. 1952.Agood pecan soil. Proc. Texas Pecan Growers Assn. 31:44-48.

Krezdorn, A.H. 1955. The nutrient status of pecan leaves in relation to alternate bearing. Proc. Texas Pecan Growers Assn. 34:43-53.

Kilham, L. 1963. Food storing of red-bellied woodpeckers. Wilson Bul. 75:227-234.

Laskey, A.R. 1942. Blue jays burying food. Migrant 13:72-73.

Laskey, A.R. 1943. The seed buried by blue jays. Migrant 14:58.

Lee, C.H. 1942. Transpiration and total evaporation, p. 259-330. In: O.E. Meinzer (ed.). Hydrology. McGraw-Hill, New York.

Lemaire, R.J. 1950. The fall, winter, and spring food habits of crows in the Baton Rouge region of Louisiana. MS thesis. La. State Univ., Baton Rouge.

Leppla, R.R. 1980. An assessment of damage to pecans by wildlife in central Oklahoma. MS thesis. Okla. State Univ., Stillwater.

Lewis, A.R. 1982. Selection of nuts by gray squirrels and optimal foraging theory. Amer. Midl. Nat. 107:250-257

Lockwood, D.W. and D. Sparks. 1978a. Translocation of ${ }^{14} \mathrm{C}$ in 'Stuart' pecan in the spring following assimilation of ${ }^{14} \mathrm{CO}_{2}$ during the previous growing season. J. Amer. Soc. Hort. Sci. 103:38-45.

Lockwood, D.W. and D. Sparks. 1978b. Translocation of ${ }^{14} \mathrm{C}$ from tops and roots of pecan in the spring following assimilation of ${ }^{14} \mathrm{CO}_{2}$ during the previous growing season. J.Amer. Soc. Hort. Sci. 103:45-49.

Loustalot, A.J. 1945. Influence of soil moisture conditions on apparent photosynthesis and transpiration of pecan leaves. J. Agr. Res. 71:519-532.

Lyr, H. and G. Hoffmann. 1967. Growth rates and growth periodicity of tree roots. Intl. Rev. For. Res. 2:181-206.

Maggio, R.C., M.K. Harris, S.J. Ingle, and M.R. Davis. 1991. A summary of the location, abundance, distribution, and condition of Carya on the Brazos and Colorado River Systems in Texas. Texas Agr. Expt. Sta. Misc. Publ. 1703.

Malstrom, H.L. 1974. The relationship of stored reserves to yield in mature pecan trees. Proc. Western Pecan Conf. 8:65-69

Manchester, S.R. 1987. The fossil history of the Juglandaceae. Monogr. Systematic Bot. 21:1-37. Missouri Bot. Gardens, St. Louis.

Marquard, R.D. 1988. Outcrossing rates in pecan and the potential for increased yields. J. Amer. Soc. Hort. Sci. 113:84-88.

Michaux, F.A. 1904. Journal of Andre Michaux, 1793-1796, p. 27-306. In R.G. Thwaites (ed.). Early western travels, 1748-1846. vol. 3. Clark, Cleveland, Ohio.

Michigan State Board Agr. 1898. Thirty-sixthAnnu. Rpt. Mich. State Board Agr., Lansing.

Middleton, R.G., M.M. Blevins, E.H. Smith, R.O. Neal, and W.S. Carson. 1968. Soil survey of Dougherty County, Georgia. U.S. Dept. Agr. Soil Conservation Serv., Wash. D. C.

Miyamoto, S. 1983. Consumptive water use of irrigated pecans. J. Amer. Soc. Hort. Sci. 108:678-681.

Miller, E.C. 1938. Plant physiology. McGraw-Hill, 
New York.

Murray, M.L. 1975. An assessment of damage to Louisiana pecan orchards by the common crow (Corvus brachyrhynchos). MS thesis. La. State Univ., Baton Rouge.

McHatton, T.H. 1957. The history, distribution and naming of the pecan (Hicoria pecan). Proc. S.E. Pecan Growers Assn. 50:10-34.

McMurran, S.M. 1919. Pecan rosette in relation to soil deficiencies. U.S. Dept. Agr. Bul. 756.

McRoberts, M.H. 1975. Food storage and winter territory in red-headed woodpeckers in northwestern Louisiana. Auk 92:382-385.

Nelson, T.C. 1965. Silvical characteristics of commercial hickories. Hickory task forest report 10, S.E. For. Expt. Sta., Forest Serv., U.S. Dept. Agr.

Nixon, C.M., M.W. McCain, and R.W. Donohoe. 1975. Effects of hunting and mast crops on a squirrel population. J. Wildl. Mgt. 39:1-25.

Nesbitt, M. 1997. Hurricane Danny slashes south Alabama crop. Pecan S. 30(7):17.

Payne, J.A., H.L. Malstrom, and G.E. KenKnight. 1979. Insect pests and diseases of the pecan. U.S. Dept. Agr. Res. Ser., ARS-S-5.

Payne, J.A. and J. Wells. 1984. Toxic Penicilla isolated from lesions of kernel-spotted pecans. Environ. Entomol. 13:1609-1612.

Pecan Quarterly. 1976. Our cover. The Pecan Quart. 10(1):2.

Peet, R.K. and N.L. Christensen. 1980. Succession:A population process. Vegetatio 43:131-140.

Pelham, J.L. 1928. Pecan root observations and their relation to cultural practice. Natl. Pecan Growers Assn. Bul. 27:30-135.

Pilkinton, J.A., E.H. Smith, and R.O. Neal. 1974. Soil Survey of Schley and Sumter Counties, Georgia. U.S. Dept. Agr. Soil Conservation Ser., Wash. D. C.

Putnam, J.A. and H. Bull. 1932. The trees of the bottomlands of the Mississippi River Delta Region. S. For. Expt. Sta., For. Serv., U.S. Dept. Agr. Occasional paper 27.

Putnam, J.A, G.M. Furnival, and J.S. McKnight. 1960. Management and inventory of southern hardwoods. U.S. Dept. Agr. Hdkb. 181.

Ranney, J.W., M.C. Bruner, and J.B. Levenson. 1981. The importance of edge in the structure and dynamics of forest islands, p. 67-95. In: R.L. Burgess and D.T. Sharpe (eds.). Forest island dynamics in man-dominated landscapes. Springer-Verlag, New York.

Reed, C.A. 1926. Pecan trees require abundant sunshine and space, p. 571-574. In: W.M. Jardine (ed.). Year book of agriculture. U.S. Dept. Agr., Wash., D.C.

Reid, W. 1985. Profits from native pecans. Annu. Rpt. N. Nut Growers Assn. 76:77-83.

Reid, W. 1997. Looking for native wisdom. Pecan S. 30(1):4-5.

Reid, W., S.M. Huslig, M.W. Smith, N.O. Maness, and J.W. Whitworth. 1993. Fruit-removal time influences return bloom in pecan. HortScience 28:800-802.

Reighard, G.L. 1990. Nursery characteristics of seedling pecan rootstocks. Annu. Rpt. N. Nut Growers Assn. 81:16-19.

Ridley, H.N. 1930. The dispersal of plants throughout the world. Reeve Co., Kent, England.

Romberg, L.D. 1944. Some characteristics of the juvenile and bearing pecan tree. Proc. Amer. Soc. Hort. Sci. 44:255-259.

Romberg, L.D. 1968. Pecan varieties in 1968. Proc. S.E. Pecan Growers Assn. 61:56-65.

Romberg, L.D. and C.L. Smith. 1946. Effects of cross-pollination, self-pollination, and sib-pollination on the dropping, volume, kernel development of pecan nuts and on the vigor of seedlings. Proc. Amer. Soc. Hort. Sci. 47:130-138.
Romer, A.S. 1966. Vertebrate palenotology. 3rd ed. Univ. Chicago Press, Chicago.

Rosborough, J.F., C.L. Smith, and L.D. Romberg. 1946. The pecan in Texas. Texas Agr. Ext. Bul. 120 .

Sargent, C.S. 1918. Notes on North American trees. II. Carya. Bot. Gaz. 66:229-258.

Sargent, C.S. 1933. Manual of the trees of North America. Houghton Mifflin, Boston.

Schnell, R.L. 1978. Biomass estimates of hickory tree components. Tenn. Valley Auth. Tech. Note B30.

Skinner, J.J. and J.B. Demaree. 1926. Relation of soil conditions and orchard management to the rosette of pecan trees. U.S. Dept. Agr. Bul. 1378.

Skinner, J.J., E.D. Fowler, and A.O. Alben. 1938. Pecan soils of the Gulf and Southeastern States and maintenance of their fertility. U.S. Dept. Agr. Cir. 492.

Sitton, B.G. 1931. A preliminary report on the relation of foliage to filling of the pecan. Proc. Natl. Pecan Growers Assn. Bul. 30:120-125.

Smith, C.L. and A.J. Loustalot. 1944. Effects of harvest date and curing on the composition and palatability of pecan nuts. J. Agr. Res. 68:395-403

Smith, C.L. and J.G. Waugh. 1938. Seasonal variations in the carbohydrate and nitrogen content of roots of bearing pecan trees. J. Agr. Res. 57:449-460

Smith, M.W. and P.L. Ager. 1988. Effects of soil flooding on leaf gas exchange of seedling pecan trees. HortScience 23:370-372.

Smith, M.W. and R.D. Bourne. 1989. Seasonal effects of flooding on greenhouse-grown seedling pecan trees. HortScience 24:81-83.

Smith, M. W. and J. C. Gallott. 1990. Mechanical thinning of pecan fruit. HortScience 25:414-416.

Smith, M.W., J.A. Anderson, and BS. Parker. 1993a. Cultivar and crop load influence cold damage of pecan. Fruit Var. J. 47:214-218.

Smith, M.W., W. Reid, B. Carroll, and B. Cheary. 1993b. Mechanical fruit thinning influences fruit quality, yield, return fruit set, and cold injury of pecan. HortScience 28:1081-1084

Smith, M.W., R.W. McNew, P.L. Ager, and B.C. Cotten. 1986. Seasonal changes in carbohydrate concentration in pecan shoots and their relationship to flowering. J. Amer. Soc. Hort. Sci. 111:558-561.

Sork, V.L. 1983. Distribution of pignut hickory (Carya glabra) along a forest to edge transect and factors affecting seedling recruitment. Bul. Torrey Bot. Club 110 (4):494-506.

Sparks, D. 1968. Changes in the potassium status of the catkins, leaves, shoots, and branches of nonfruiting mature pecan trees, Carya illionensis, Koch cv. 'Stuart' as a function of physiological development. Proc. Amer. Soc. Hort. Sci. 93:215-223.

Sparks, D. 1969. Some characteristics of shoot growth of pecan trees and their implications to yield. Proc. S.E. Pecan Growers Assn. 62:55-75.

Sparks, D. 1974. The alternate fruit bearing problem in pecans. Annu. Rpt. N. Nut Growers Assn. $65: 145-158$

Sparks, D. 1975. Concentration and content of 14 elements in fruit of pecan. HortScience 10:517-519.

Sparks, D. 1977. Effects of fruiting on scorch, premature defoliation, and nutrient status of 'Chickasaw' pecan leaves. J. Amer. Soc. Hort Sci. 102:669-673.

Sparks, D. 1981. Notes on training pecan trees. Pecan S. 8(5):12-21, 28-35.

Sparks, D. 1983. Alternate fruit bearing in nut trees. Annu. Rpt. N. Nut Growers Assn. 74:197-230
Sparks, D. 1986a. Effect of magnesium sulfate sprays on growth and elemental concentration of pecan seedling. HortScience 21:108-109.

Sparks, D. 1986b. Growth and nutrition of pecan seedlings from potassium phosphate foliar sprays. HortScience 21:452-453.

Sparks, D. 1986c. Pecan, p. 323-339. In: S.P. Monselise (ed.). Handbook of fruit set and development. CRC Press, Boca Raton, Fla.

Sparks, D. 1987. Apparent effect of zinc treatment on the growth rate of pecan production and yield. HortScience 22: 899-901.

Sparks, D. 1988. Effect of shoot vigor on pistillate flower production and abortion in 'Stuart' pecan. HortScience. 23:570-571.

Sparks, D. 1989a. Drought stress induces fruit abortion in pecan. HortScience 24:78-79.

Sparks, D. 1989b. Pecan nutrition-A review. Proc S.E. Pecan Growers Assn. 82:101-122.

Sparks, D. 1989c. Predicting nut maturity of the pecan from heat units. HortScience 24:454-455.

Sparks, D. 1990. Interrelationships of precocity, prolificness, and nut quality in pecan. HortScience 25:297-299.

Sparks, D. 1991a. Geographical origin of pecan cultivars influences time required for fruit development and nut size. J. Amer. Soc. Hort. Sci. 116:627-631

Sparks, D. 1991b. Cultural practices, p. 22-33. In: B Wood and J.A. Payne (eds.). Pecan husbandry: Challenges and opportunities. 1st Natl. Pecan Wkshp. Proc. U.S. Dept. Agr., Agr. Res. Ser., ARS-96.

Sparks, D. 1992a. Pecan cultivars - The orchard's foundation. Pecan Productions Innovations, Watkinsville, Ga.

Sparks, D. 1992b. Stress factors affecting the Georgia pecan crop in 1991 and fruit set in 1992. Annu. Rpt. N. Nut Growers Assn. 83:57-62.

Sparks, D. 1992c. In pursuit of a better pecan cultivar. Fruit Var. J. 46:174-182.

Sparks, D. 1992d. Abnormal flowering in pecan associated with freezing temperatures. HortScience 27:801-803.

Sparks, D. 1993. Chilling and heating model for pecan budbreak. J. Amer. Soc. Hort. Sci. 118:29-35.

Sparks, D. 1995a. Water! Water! Water! Especially in September. Pecan S. 28(7):4-5.

Sparks, D. 1995b. Nut sizing period in pecan and soil water. Annu. Rpt. N. Nut Growers Assn. 86:113-115

Sparks, D. 1995c. June-August: Period of nut sizing. Pecan S. 28(4):7,19,22.

Sparks, D. 1996. A climatic model for pecan production under humid conditions. J. Amer. Soc. Hort. Sci. 121:908-914.

Sparks, D. 1997a. A climatic model for predicting Georgia's pecan production. Proc. S.E. Pecan Growers Assn. 90:32-44.

Sparks, D. 1997b. A model for predicting pecan production under arid conditions at high elevations. J. Amer. Soc. Hort. Sci. 122:648-652.

Sparks, D. 2000a. Fruit set in pecan, Carya illinoensis, p. 35-48. In: A. Janoudi (ed.). Proceedings of the international symposium on growth and development of fruit crops. Acta Hort. 527.

Sparks, D. 2000b. Pecan in warm climate, p. 381-403. In:A. Erez (ed.). Temperate fruit crops in warm climates. Kluwer Academic Publishers, Norwell, Mass.

Sparks, D. 2001. Managing pecan nut growth. Proc. S.E. Pecan Growers Assn. 94:129-147.

Sparks, D. 2002a. Rainfall governs pecan stand homogeneity in native, wild habitats. J. Amer. Soc. Hort. Sci. 127:860-868.

Sparks, D. 2002b. Effect of topography, crop load, and irrigation on pecan nut volume and percentage kernel. Annu. Rpt. N. Nut Growers 
Assn. 93:87-92

Sparks, D. 2002c. Relative tendency of selected pecan cultivars to premature germinate. Annu. Rpt. N. Nut Growers Assn. 93:83-86.

Sparks, D. 2003a. Timing fertilizer application for pecan-Revisiting the literature. Pecan S. 36(6):12-15.

Sparks, D. 2003b. Pecan tree dieback following 1999-2002 drought associated with September rainfall. J. Amer. Pomol. Soc. 57:142-146.

Sparks, D. 2003c. Growth, flowering, and fruiting, p. 273-315. In: D.W. Fulbright (ed.). A guide to tree culture in North America, vol. 1. Northern Nut Growers Assn.

Sparks, D. 2004a. Aletter from L.D. Romberg. Pecan S. 36(12): 14, 15, 18-20.

Sparks, D. 2004b. Pecan grows towards sunlight. Pecan S. 37:24-25.

Sparks, D. and C.E. Brack. 1972. Return bloom and fruit set of pecan from leaf and fruit removal. HortScience 7:131-132.

Sparks, D. and G.D. Madden. 1985. Pistillate flower and fruit abortion in pecan as a function of cultivar, time, and pollination. J. Amer. Soc. Hort. Sci. 110:219-223.

Sparks, D. and J.A. Payne. 1977. Freeze injury susceptibility of nonjuvenile trunks in pecan. HortScience 12:497-498.

Sparks, D. and J.A. Payne. 1978. Winter injury in pecan-A review. Pecan S. 5(2):56-60, 82-88.

Sparks, D. and J.A. Payne. 1986. Note on severity of tornado damage to Stuart vs. Schley pecan trees. Annu. Rpt. N. Growers Assn. 77:79-80.

Sparks, D., J.W. Chapman, and D.W. Lockwood. 1974. Stratification promotes germination. Pecan Quart. 8(1):13.

Sparks, D., W. Reid, I.E. Yates, M.W. Smith, and T.G. Stevenson. 1995. Fruiting stress induces shuck decline and premature germination in pecan. J. Amer. Soc. Hort. Sci. 120:43-53.

Sparks, D. and I.E. Yates. 1995. Anatomy of shuck abscission in 'Desirable' pecan. J. Amer. Soc. Hort. Sci. 120:790-797.

Stapanian, M.A. and C.C. Smith. 1978. A model for seed scatterhoarding: coevolution of fox squirrels and black walnuts. Ecology 59:884-896.

Stokes, M., T. Harlan, M. Harris, and J.B. Storey. 1995. Datability of pecan tree rings. HortScience 30:523-524.

Stone, D.E. 1973. Patterns in the evolution of amentiferous fruits. Brittonia 25:371-384.

Streets, R.B. and H.E. Bloss. 1973. Phymatotrichum root rot. Amer. Phytopathol. Soc. Monogr. 8, St. Paul, Minn.

Stuckey, H.P. 1916. The two groups of varieties of the Hicoria pecan and their relation to self-sterility. Ga. Expt. Sta. Bul. 116.

Swain, T. 1965. The tannins, p. 552-580. In: J. Bonner and J.E. Varner (eds.). Plant biochemistry. Academic Press, New York.

Tedders, W.L. and J.S. Smith. 1976. Shading effect on pecan by sooty mold growth. J. Econ. Entomol. 69:551-553.

Tedders, W.L. and B.W. Wood. 1985. Estimate of the influence of feeding by Monelliopsis pecanis and Monellia caryella (Homoptera:Aphididae) on fruit, foliage carbohydrate reserves, and tree productivity of mature 'Stuart' pecans. J. Econ. Entomol. 78:642-646.

Tedders, W.L., V.R. Calcote, and J.A. Payne. 1970. A method for rapid germination of pecan seed.
Pecan Quart. 4(4):11.

Thor, C.J. and C.L. Smith. 1935. A physiological study of seasonal changes in the composition of the pecan during fruit development. J. Agr. Res. 50:97-121.

Tisdale, S.M., W.L. Nelson, and J.D. Beaton. 1985. Soil fertility and fertilizers. 4th ed. Macmillan, New York.

Toumey, J.W. 1929. Initial root habit in American trees and its bearing on regeneration. Proc. 4th Intl. Bot. Congr. 1:713-728.

True, R.H. 1917. Notes on the early history of the pecan in America. Annu. Rpt. Smithsonian Inst.

U.S. Department of Agriculture Bureau of Plant Industry. 1931. First annual report. Pecan investigation, Austin and Brownwood, Texas. U.S Dept. Agr. Bur. Plant Ind., Wash., D.C.

Vander Wall, SB. 1990. Food hoarding in animals. Univ. Chicago Press, Chicago.

Varner, J.E. 1965. Seed development and germination. p. 763-792. In: J. Bonner and J.E. Varner (eds.). Plant biochemistry. Academic Press, New York.

Von Ohlen, F.W. 1931. A microchemical study of soybean during germination. Amer. J. Bot. 18:30-49.

Wang, T. 1987. Pecan shells as an organic component of container potting media. MS thesis. Univ. Ga., Athens.

Watt, B.K. and A.L. Merrill. 1963. Composition of foods. U.S. Dept. Agr. Hdbk. 8.

Wazir, F.K., M.W. Smith, and S.W. Akers. 1988 Effects of flooding and soil phosphorus levels on pecan seedlings. HortScience 23:595-597.

Wells, J.M. and J.A. Payne. 1976. Toxigenic species of Pencillium, Fusarium, and Aspergillus from weevil-damaged pecan. Can. J. Microbiol. 22:281-285.

Werchan, L.E., A.C. Lowther, and R.N. Ramsey. 1974. Soil survey of Travis County, Texas. U.S. Dept. Agr. Soil Conservation Serv., Wash. D.C.

Westwood, M.N. 1978. Temperate-zone pomology. Freeman, San Francisco.

Wetzstein, H.Y. 1989. Pollination and development of the receptive stigma in pecan, Carya illinoensis. Acta Hort. 240: 193-196.

Wetzstein, H.Y. and D. Sparks. 1983. Morphology of pistillate flowers differentiation in pecan (Carya illinoensis). J. Amer. Soc. Hort. Sci. 108:997-1003.

Wetzstein, H.Y. and D. Sparks. 1984. The morphology of staminate flower differentiation in pecan. J. Amer. Soc. Hort. Sci. 109:245-252.

Wetzstein, H.Y., D. Sparks, and G.A. Lang. 1983. Cotyledon detachment and growth of pecan seedlings. HortScience 18:331-333.

White,A.W. 1982. Effects of topsoil-subsoil fertilizer and lime amendments on top and root growth of 'Stuart' pecan seedlings in simulated Norfolk soil profile. HortScience 17:380-381.

White, Jr., H.B. 1958. Fat utilization and composition in germinating cotton seeds. Plant Physiol. 33:218-226.

White, A.W. and J.H. Edwards. 1978. Soil profile distribution and seasonal growth of pecan roots. Proc. S.E. Pecan Growers Assn. 71:47-53.

Whitehead, D.R. 1969. Wind pollination in the angiosperms: evolutionary and environmental considerations. Evolution 23:28-35.

Williams, J.A. 2002. Appalachia-A history. Univ.
N.C. Press, Chapel Hill.

Wolstenholme, B.N. 1969. Effect of self- and crosspollination on fruit set and nut drop of the pecan at Pietermaritizburg. Agroplante 1:189-194.

Wolstenholme. B.N. 1970. Patterns of budbreak in a pecan cultivar/cultural experiment under dryland conditions. Agroplante 2:61-66.

Wolstenholme, B.N. 1974. Effect of stratification and temperature on germination of pecan nuts. Citrus and Sub-trop. Fruit J. (Sept.):9, 10, 20.

Wolstenholme, B.N. 1979. The ecology of pecan trees, part 1. Characteristics of the native habitat. Pecan Quart. 13(2):32-35.

Wood, B.W. 1986. Cold injury susceptibility of pecan as influenced by cultivar, carbohydrates, and crop load. HortScience 21:285-286.

Wood, B.W. 1989. Pecan production responds to root carbohydrates and rootstock. J. Amer. Soc. Hort. Sci. 114:233-228.

Wood, B.W. 1993. Production characteristics of the United States pecan industry. J. Amer. Soc. Hort. Sci. 118:538-545.

Wood, B.W. 1995. Relationship of reproductive and vegetative characteristics of pecan to previous fruit development and post ripening foliation period. J. Amer. Soc. Hort. Sci. 120:635-642.

Wood, B.W. and R.D. Marquard. 1992. Estimates of self-pollination in pecan orchards in the southeastern United States. HortScience 27:406-408.

Wood, B.W. and C.C. Reilly. 2001. Atypical symptoms of cold damage to pecan. HortScience 36:298-301.

Wood, B.W. and W.L. Tedders. 1982. Effects of an infestation of blackmargined aphid on carbohydrates in mature 'Stuart' pecan. HortScience 17:236-238.

Woodroof, J.G. 1924. The development of pecan buds and the quantitative production of pollen. Ga. Expt. Sta. Bul. 144.

Woodroof, J.G. 1930. Studies of the staminate inflorescence and pollen of Hicoria pecan. J. Agr. Res. 40:1059-1104.

Woodroof, J.G. 1933. Relation of the root system of pecan trees to nursery and orchard practices. $\mathrm{Ga}$. Expt. Sta. Bul. 176.

Woodroof, J.G. and N.C. Woodroof. 1926. Fruit-bud differentiation and subsequent development of the flowers in the Hicoria pecan. J. Agr. Res. 33:677-685.

Woodroof, J.G. and N.C. Woodroof. 1934. Pecan root growth and development. J. Agr. Res. 49:511-530.

Worley, R.E. 1979. Fall defoliation date and seasonal carbohydrate concentration of pecan wood tissue. J. Amer. Soc. Hort. Soc. 104:195-199.

Worley, R.E. 1982. Tree yield and nut characteristics of pecan with drip irrigation under humid conditions. J. Amer. Soc. Hort. Sci. 107:30-34.

Worley, R.E., S.A. Harmon, and R.L. Carter. 1974. Effect of repeated $\mathrm{N}, \mathrm{P}, \mathrm{K}$, and lime applications on soil $\mathrm{pH}, \mathrm{P}$, and $\mathrm{K}$ under old and young pecan trees. J. Amer. Soc. Hort. Sci. 99:57-62.

Worthington, J.W., J.Lasswell, and M.J. McFarland. 1987. Irrigation-The trees' prospective. Pecan S. 21(1): 4-8.

Yates, I.E. and D. Sparks. 1993. Environmental regulation of anther dehiscence and pollen germination in pecan. J. Amer. Soc. Hort. Sci. 118:699-706.

Yates, I.E. and D. Sparks. 1994. Anatomy differs for aborting and nonaborting pistillate flowers in pecan. J. Amer. Soc. Hort. Sci. 119:949-955. 